\title{
Drop Impacts on Electrospun Nanofiber Membranes ${ }^{\dagger}$
}

\author{
R.P. Sahu ${ }^{a}$, S. Sinha-Ray ${ }^{a}$, A.L. Yarin ${ }^{\text {a,b }}$, B. Pourdeyhimic \\ ${ }^{a}$ Department of Mechanical and Industrial Engineering, \\ University of Illinois at Chicago, \\ 842 W. Taylor St., Chicago IL 60607-7022. Tel: (312)996-3472 \\ E-mail: ayarin@uic.edu \\ ${ }^{b}$ Center for Smart Interfaces, Technische Universität Darmstadt \\ Petersenstr. 32, 64287 Darmstadt, Germany \\ `3427 The Nonwovens Institute, Box 8301, \\ North Carolina State University \\ Raleigh NC 27695-8301
}

This work reports a systematic study of drop impacts of polar and non-polar liquids onto different electrospun nanofiber membranes (of 8-10 $\mu \mathrm{m}$ thickness and pore sizes of 3-6 $\mu \mathrm{m}$ ) with an increasing degree of hydrophobicity. The liquids studied were water, FC 7500 (Fluorinert fluid) and hexane. The nanofibers used were electrospun from Polyacrylonitrile (PAN), Nylon 6/6, Polycaprolactone (PCL) and Teflon. It was found that for any liquid/fiber pair there exist a threshold impact velocity $(\sim 1.5-3 \mathrm{~m} / \mathrm{s})$ above which water penetrates membranes irrespective of their hydrophobicity. The other liquids (FC 7500 and hexane) penetrate the membranes even easier. The low surface tension liquid, FC 7500, left the rear side of sufficiently thin membranes as a millipede-like system of tiny jets * To whom correspondence should be addressed. E-mail: ayarin@uic.edu; Phone: +1(312) 996-3472. Fax: +1(312) 413-0447.

${ }^{\dagger}$ Electronic Supplementary Information (ESI) and Electronic Supplementary Movie (ESM) are available. 
protruding through a number of pores. For such high surface tension liquid as water, jets immediately merged into a single bigger jet, which formed secondary spherical drops due to capillary instability. No mechanical damage to the nanofiber mats after liquid perforation was observed. A theoretical estimate of the critical membrane thickness sufficient for complete viscous dissipation of the kinetic energy of penetrating liquid is given and corroborated by the experimental data.

\section{Introduction}

Questions on penetration of liquid drops into porous media arise in relation to filtration through porous nonwoven membranes, coalescence filters and ordered fibrous media with fiber diameters from several tens of micron down to electrospun nanofibers ${ }^{1-9}$. Single collector capture mechanisms intercept a single drop per event, at one point on a fiber or at the pore surface. Multi-fiber capture mechanisms such as straining, pore bridging, and pore blocking are also present in practice. Various physical mechanisms of drop interception and drainage are discussed in the above-mentioned references. Some approaches to the development of novel coalescence filters were triggered by the development of a number of the so-called superhydrophobic materials with high static contact angles of more than $150-160^{\circ}$, in particular, those mimicking the lotus effect ${ }^{10-12}$. Drop impacts on porous nonwovens are characteristic not only of coalescence filtration but also of protective clothes used as a barrier for warfare liquid aerosols, e.g. such nerve agents as $\mathrm{VX}^{13}$.

Nonwovens are not only used to intercept impacting drops, but also to deliver them to a surface on which they are deposited as a coating, as in the recently introduced method of cooling of high-heat-flux electronic devices and server rooms through electrospun nanofiber mats ${ }^{14}$. The 
latter work, as well as the accompanying works ${ }^{15-18}$, in fact, demonstrated that the concept of hydrophobic micro- and nano-textured filters and porous coatings might be intrinsically vulnerable, since it is based on a misconception of static hydrophobicity. For example, in Ref. 15 it was shown that a millimiter-sized water drop softly deposited on a nonwoven electrospun nanofiber mat produced from PAN stayed almost spherical for several minutes. A completely different outcome was observed when a water drop of $2 \mathrm{~mm}$ in diameter impacted onto the same nanofiber mat at a speed of $2 \mathrm{~m} / \mathrm{s}$. In the latter case, the drop first rapidly spreads on a nanofiber mat surface as on a dry, rigid substrate but then remains pinned in the spread-out configuration and does not recede or bounce, as on a completely wettable substrate. Pinning of spread-out drops after the spreading stage of impact was used in Refs. 14-18 to facilitate drop cooling of hot surfaces coated with nanofiber mats - a paradoxical situation because cooling was intensified by putting an insulation-like "furry overcoat" on a hot surface.

The observations with the help of high-speed cameras revealed many intriguing features of drop impact onto solid and liquid surfaces and significantly facilitated our understanding of this fascinating phenomenon ${ }^{19,20}$. A recent ramification of such investigations encompassed drop impact onto nano-textured porous surfaces ${ }^{14-18,21-26}$. Such impacts are accompanied by non-trivial physical effects, which require understanding. In addition to the interesting physical aspects, the attention to drop impacts onto nano-textured porous surfaces was fueled by the interest in developing novel water-repelling surfaces, with electrospun Teflon nanofiber mats being a natural candidate ${ }^{23}$. On the other hand, drop impact onto nanofiber mats (both electrospun or not) revealed that under certain conditions they promote dynamic wettability rather than repelling water ${ }^{14-18,22,26}$. Moreover, it was recognized that due to the large disparity between the drop and the inter-fiber pore sizes (the drop diameter $\mathrm{D}$ of the order of $1 \mathrm{~mm}$ and the pore size $\mathrm{d}$ of the 
order of 1-10 $\mu \mathrm{m}$ ), liquid accumulates the kinetic energy at the pore entrances and protrudes into them with a speed of the order of $(D / d) V \approx 100 \mathrm{~V}$ where $\mathrm{V}$ is the impact velocity. This effect is reminiscent of the mechanism of formation of shaped-charge (Munroe) jets and is kindred to the widely-known way of opening wine bottles by a sufficiently strong palm hit onto their bottom. Above the threshold impact velocity, in the dynamic wettability domain, such high speeds of liquid penetration and short times involved (on the scale of several milliseconds) preclude any manifestations of such wettability-related effects as the time dependence of the retention force observed on the scale of $10 \mathrm{mins}^{27,28}$. A possible directionality of wettability-driven liquid spreading on non-uniform electrospun mats ${ }^{15}$ or slanted nanohairs ${ }^{29,30}$ are slow phenomena (on the scale of $10 \mathrm{~s}$ ), which are immaterial in the domain of the dynamic wettability (on the scale of a few milliseconds).

The idea that it might be possible to achieve an ultimate fluid-repellent coalescence filter made of electrospun Teflon or other superhydrophobic nanofibers is of significant interest, sounds attractive and is widely discussed. However, as the above-mentioned results on drop impact on electrospun nanofiber mats show, static hydrophobicity of such mats does not characterize dynamic behavior under the conditions of drop impact, and cannot prevent water penetration into these nanofiber mats. The latter means that dynamic transition from the CassieBaxter to Wenzel state is possible for such systems, even though the static one is not. This effect precludes development of ideal, absolutely water repellent filter media, or their front layers, but maybe such highly hydrophobic materials as Teflon-coated nanofibers ${ }^{23}$ hold potential? The answer to this question will be negative according to the results described below.

The aim of the present work is to elucidate the outcomes of drop impacts of polar and nonpolar fluids onto electrospun nanofiber membranes with different degrees of wettability. The 
approach and results are absolutely novel, since none of the above-mentioned works dealt with nanofiber membranes, as well as the dynamic penetration mechanisms overbearing wettability were not fully demonstrated so far, as to our knowledge. The questions explored in the present work need to be resolved, first of all, to address the following general scientific issues. (i) Can hydrophobicity prevent water penetration through a layer of porous medium, and especially through a layer of a nano-textured porous medium? (ii) Under what conditions hydrophobicity or hydrophilicity become secondary, and water penetration is fully dominated by the dynamic effects? (iii) Does hydrophobicity of skeleton of a porous medium with interconnected pores shed any light on its interaction with the impacting drops? (iv) Can superhydrophobicity of the skeleton prevent water penetration due to drop impact? (v) What is the role of liquid viscosity under the conditions of the dynamic penetration? In addition, to these basic scientific questions, it is emphasized that the answers to them are of significant importance for such applications as drop and spray cooling of high-heat-flux microelectronic, optoelectronic and radiological devices, as well as server rooms, coalescence filter media, membranes and nonwovens.

\section{Experimental}

\subsection{Materials}

Polyacrylonitrile (PAN-molecular weight - $150 \mathrm{kDa}$ ) was obtained from Polymer Inc. NN, Dimethyl Formamide (DMF) anhydrous 99.8\%, Dichloromethane anhydrous 99.8\% (MC), Polycaprolactone (PCL-molecular weight- 80kDa), Formic Acid and Nylon 6/6 (molecular weight - $22 \mathrm{KDa}$ ) were obtained from Sigma Aldrich. $1 \mathrm{wt} \%$ Teflon AF 2400 was obtained from DuPont. Teflon AF 1600 in powder form was generously donated by DuPont. FC 40 (also termed Fluorinert Fluid) and FC 7100, FC 7200, FC 7300, FC 7500 and FC 7600 (also termed Novec Engineered Fluids) were generously donated by 3M Company. FC-40 was used to 
dissolve Teflon solutions. Nylon grids (a filter medium) of $20 \mu \mathrm{m}$ average pore size, with a pitch of $40 \mu \mathrm{m}$ and $60 \mu \mathrm{m}$ in orthogonal directions and $34 \mu \mathrm{m}$ in thickness, which was used as a substrate for the electrospun nanofiber mats to prevent vibrations after drop impact was obtained from "Small Parts". The Nylon grids thus received were rinsed with de-ionized water and dried prior to use to remove ethylene oxide with which they were treated by the manufacturer.

\subsection{Preparation of Solutions}

Polymer solutions used for electrospining of PAN nanofiber mats were prepared from 8 wt\% PAN dissolved in DMF. Polymer solutions used to electrospin Nylon 6/6 were prepared from $23 \mathrm{wt} \%$ Nylon 6/6 dissolved in Formic Acid. Solution of $13 \mathrm{wt} \%$ PCL was prepared by dissolving PCL in DMF and MC in the ratio of $75 / 25$ by weight.

The difficulty with electrospinning Teflon is associated with its low dielectric constant and the boiling point of its best solvent, FC 40. As recommended in Ref. 31, FC 40 was blended with the other Novec Engineered fluids to increase the dielectric constant of the solvent. The relative dielectric permittivities and boiling points of different Novec Engineered fluids, Fluorinert fluids and Teflon AF 1600 are listed in Table 1 according to the values provided by the supplier. Different Teflon solutions were prepared by dissolution in blends of $20 \%$ of FC 40 and $80 \%$ of different Novec Engineered fluids. The polymer solutions were prepared at $45{ }^{\circ} \mathrm{C}$ overnight under agitation until a uniform solution was obtained. It was found that the solutions containing FC 7100 and FC 7200 dried at the tip of the electrospinning nozzle. This can be attributed to the fact that these fluids have low boiling point, which results in a high evaporation rate at a given temperature. It was also found that although FC 7600 had a comparatively higher boiling point, the solution made by using FC 7600 was not a homogenous one. In addition, this solution started 
precipitating within 30-40 min after being removed from the hotplate. Therefore, only solutions based on FC 7300 (whose boiling point is close to that of water) worked properly in electrospinning. The dielectric permittivity of FC 7300 is slightly lower than that of FC 7100 . However, the use of FC 7300 was preferable to prevent the accumulation and drying at the tip of the electrospinning nozzle in order to have a robust electrospinning process. Therefore, for electrospinning, $5 \mathrm{wt} \%$ solution of Teflon AF 1600 was prepared by dissolving Teflon in solvent comprised of $20 \mathrm{wt} \%$ FC 40 and $80 \mathrm{wt} \%$ FC 7300.

Table 1 Properties of Teflon AF and the solvents tested for its electrospinning

\begin{tabular}{|l|c|c|c|c|c|c|}
\hline & $\begin{array}{c}\text { Teflon } \\
\text { AF } \\
\mathbf{1 6 0 0}\end{array}$ & FC 40 & FC 7100 & FC 7200 & FC 7300 & FC 7600 \\
\hline $\begin{array}{l}\text { Dielectric } \\
\text { permittivity }\end{array}$ & 1.93 & 1.9 & 7.4 & 7.3 & 6.1 & 6.4 \\
\hline $\begin{array}{l}\text { Boiling } \\
\text { point }\left({ }^{\circ} \text { C) }\right.\end{array}$ & - & 155 & 61 & 76 & 98 & 131 \\
\hline
\end{tabular}

\subsection{Electrospinning}

All the solutions were electrospun directly onto square sized bare Nylon grids of the size $1 " \times 1 "$. Electrospinning was carried out using a standard single nozzle setup. Different parameters used for electrospinning of different polymer solutions are listed in Table 2.

Table 2 Electrospinning parameters

\begin{tabular}{|c|c|c|c|c|c|}
\hline $\begin{array}{c}\text { Polymer } \\
\text { solution }\end{array}$ & $\begin{array}{c}\text { Concentration } \\
(\mathrm{wt} \%)\end{array}$ & $\begin{array}{c}\text { Flow rate } \\
(\mathrm{ml} / \mathrm{h})\end{array}$ & $\begin{array}{c}\text { Electric field strength } \\
\mathbf{( k V / c m )}\end{array}$ & $\begin{array}{c}\text { Inter-electrode } \\
\text { distance } \\
(\mathbf{c m})\end{array}$ & Needle \\
\hline
\end{tabular}




\begin{tabular}{|c|c|c|c|c|c|}
\hline PAN & 8 & 0.7 & 1 & 15 & $18 \mathrm{G}$ \\
\hline Nylon 6/6 & 23 & 0.3 & 1.5 & 10 & $25 \mathrm{G}$ \\
\hline PCL & 13 & 0.8 & 1 & 15 & $18 \mathrm{G}$ \\
\hline $\begin{array}{c}\text { Teflon AF } \\
1600\end{array}$ & 5 & 0.2 & 2 & 8 & $18 \mathrm{G}$ \\
\hline
\end{tabular}

\subsection{Contact Angle}

Contact angles of water drops on cast samples of different polymers on a glass slide were measured and listed in Table 3. The polymers used in this study span the partially wettable to hydrophobic regime.

Table 3 Static contact angle of water on cast polymer films.

\begin{tabular}{|l|l|l|l|c|}
\hline Polymer & Nylon 6/6 & PAN & PCL & Teflon AF 1600 \\
\hline Contact angle & $30^{\circ}-40^{\circ}$ & $40^{\circ}-45^{\circ}$ & $95^{\circ}-105^{\circ}$ & $115^{\circ}-120^{\circ}$ \\
\hline
\end{tabular}

\subsection{Preparation of Teflon-Coated Nylon Grids}

To prepare Nylon grids coated with Teflon, the following procedure was implemented. An original $1 \mathrm{wt} \%$ Teflon AF 2400 solution in FC 40 was diluted using FC 40 solvent to $0.1 \mathrm{wt} \%$. Then, a bare Nylon grid was dipped into the diluted Teflon solution. After that, the grid was wiped gently to avoid the formation of a thick Teflon film that might block the pores. The dried Teflon-coated Nylon grid was then subjected to air blowing to ensure the pore size to be the same as in the bare Nylon grids.

\subsection{Drop Impact Experiments}


Electrospun nanofiber membranes deposited onto Nylon grids were installed in the experimental setup schematically shown in Fig. 1. It consisted of an adjustable platform, a syringe pump, a high speed CCD camera (RedLake Motion Pro Camera), an external light source, a computer and a stand assembly. Samples were placed centrally on the adjustable platform which can be moved in the X-Y direction (in the horizontal plane). The supporting grids prevented any visible vibrations following drop impact onto the electrospun mats. On the other hand, the grids could not affect liquid penetration, since the hydraulic resistance of the grids was much lower than that of the mats. The high speed CCD camera recorded the dynamics of drop impact onto the nanofiber mats supported by Nylon grids at $500 \mathrm{fps}$ with a shutter speed of 1/6000 s. To ensure reproducibility of drop sizes, liquids were delivered by syringe pump with a constant flow rate of $5 \mathrm{ml} / \mathrm{hr}$. A $25 \mathrm{G}$ needle was used to form water drops by gravity-driven dripping, whereas an $18 \mathrm{G}$ needle was used to form FC 7500 and hexane drops. The images recorded by the CCD camera were processed by using ImageJ, Matlab and Adobe Photoshop CS2. In all the experiments drop size was close to $1 \mathrm{~mm}$ in diameter and kept unchanged. Drops were dripping from different heights in the range 5-60 cm, which is equivalent to increasing the drop impact velocity from $1 \mathrm{~m} / \mathrm{s}$ to $3.46 \mathrm{~m} / \mathrm{s}$ in each case of the 8 cases described in the following paragraph.

The experiments were done in the following succession: (i) Hydrophilic bare Nylon grids were used as membranes, while water drops impacted onto them. (ii) Hydrophobic Teflon-coated grids were used as membranes, while water drops impacted onto them. Note, that water is a polar, high surface tension fluid. (iii) Drops of a non-polar, low surface tension Fluorinert fluid FC 7500 impacted onto bare Nylon grids and Teflon-coated grids. (iv) Drops of another nonpolar, relatively low surface tension fluid, hexane, were impacted onto bare Nylon grids and 
Teflon-coated grids. (v) Water drops were impacted onto partially wettable electrospun PAN nanofiber mats. (vi) Water drops were impacted onto partially wettable electrospun Nylon 6/6 nanofiber mats. (vii) Water drops were impacted onto hydrophobic electrospun PCL nanofiber mats. (viii) Water drops were impacted onto superhydrophobic Teflon nanofiber mats. This succession of the experiments was chosen to explore the effect of the grid wettability (partially hydrophilic/superhydrophobic), of the liquid properties (in particular, high/low surface tension, polar/non-polar), and of the nanofiber mat wettability (partially hydrophilic/hydrophobic/superhydrophobic) on the drop impact outcome. In all cases the impact velocity was gradually increased, until a threshold velocity was reached, above which liquid penetrated through the membrane irrespective of its wettability.

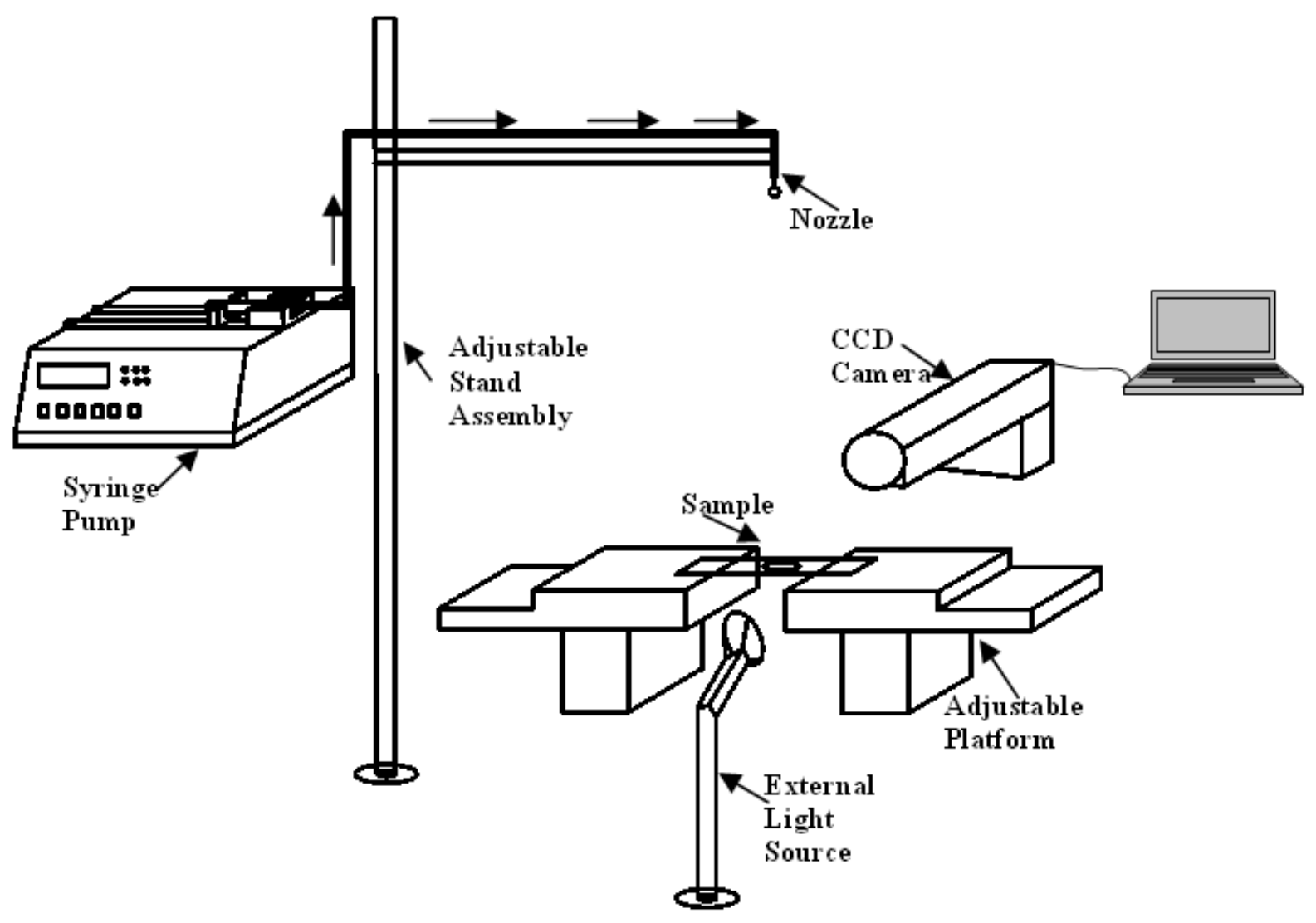

Fig. 1 Schematic of the experimental setup. 


\subsection{Microscopy}

Microscopic images were obtained using Scanning Electron Microscope (SEM) JEOL-JSM $6320 \mathrm{~F}$.

\section{Results and Discussion}

\subsection{Water Drop Impacts onto Bare Nylon Grids}

In the experiments with drop impacts onto bare Nylon grids (see the SEM image in Fig. $\mathrm{S} 1 \mathrm{a}$ in ESI), it was found that at low impact velocities $(1-2 \mathrm{~m} / \mathrm{s})$ there was no visible penetration of water drops to the other side of the grid (Fig. 2). However, it can be seen from Fig. 2b-f that although there was no penetration to the other side, the water drop did not retract, but rather was pinned, similarly to the observations of drop impacts onto nanofiber mats in Ref. 15-18.

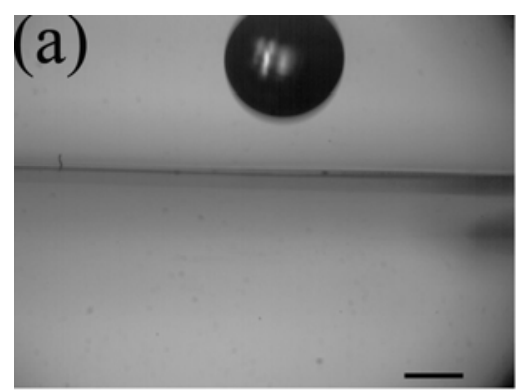

$\mathrm{t}=0 \mathrm{~ms}$

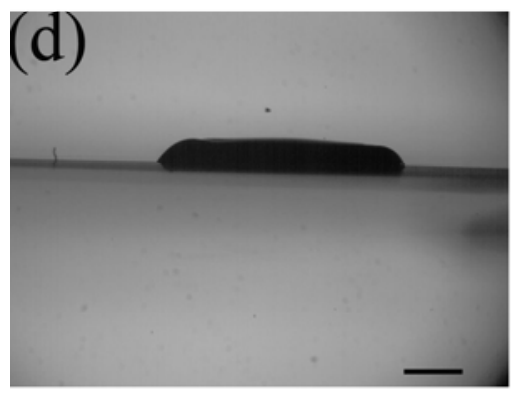

$\mathrm{t}=18 \mathrm{~ms}$

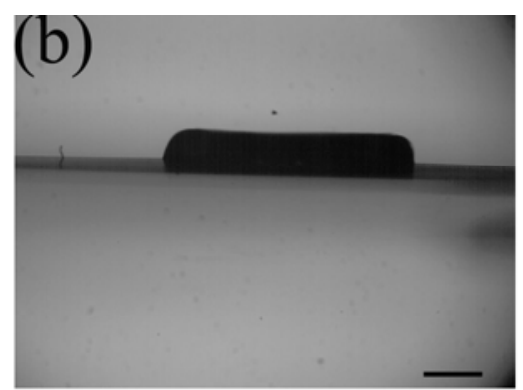

$\mathrm{t}=6 \mathrm{~ms}$

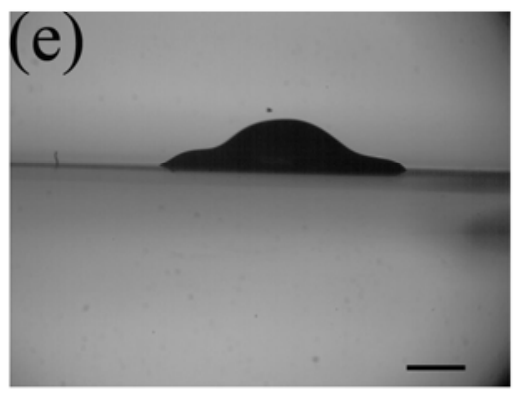

$\mathrm{t}=24 \mathrm{~ms}$

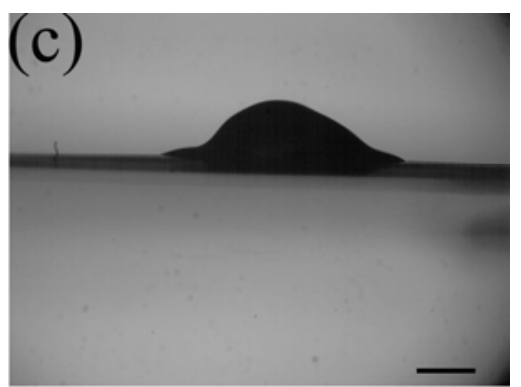

$\mathrm{t}=12 \mathrm{~ms}$

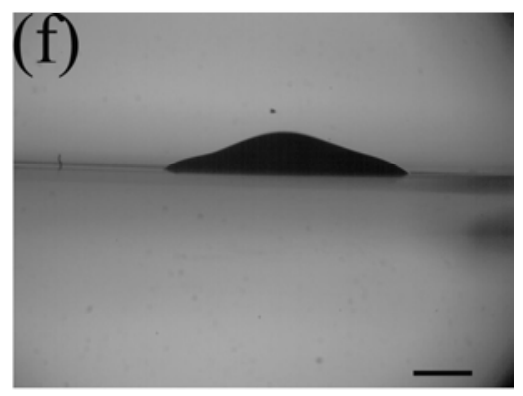

$\mathrm{t}=30 \mathrm{~ms}$ 
Fig. 2 Impact of water drop onto bare Nylon grid with low impact velocity of $1 \mathrm{~m} / \mathrm{s}$. The panels correspond to: (a) $\mathrm{t}=0 \mathrm{~ms}$, (b) $\mathrm{t}=6 \mathrm{~ms}$, (c) $\mathrm{t}=12 \mathrm{~ms}$, (d) $\mathrm{t}=18 \mathrm{~ms}$, (e) $\mathrm{t}=24 \mathrm{~ms}$ and (f) $\mathrm{t}=30$ ms. Scale bars, $1 \mathrm{~mm}$.

When the drop impact velocity was increased above $2 \mathrm{~m} / \mathrm{s}$, visible penetration of water through bare Nylon grids was observed (Fig. 3). However, it was also observed that at lower impact velocities $(2-3 \mathrm{~m} / \mathrm{s})$, after the water drop has penetrated through the Nylon grid, it mostly retracted back presumably due to the effect of the surface tension (Fig. 4a\&b). At a higher impact velocity $(3.46 \mathrm{~m} / \mathrm{s})$, a part of the water drop that penetrated through the Nylon grid did not retract back and dripped down as smaller drops (Fig. 4c\&d). It is clear that in the latter case water still had enough kinetic energy to overbear surface tension.
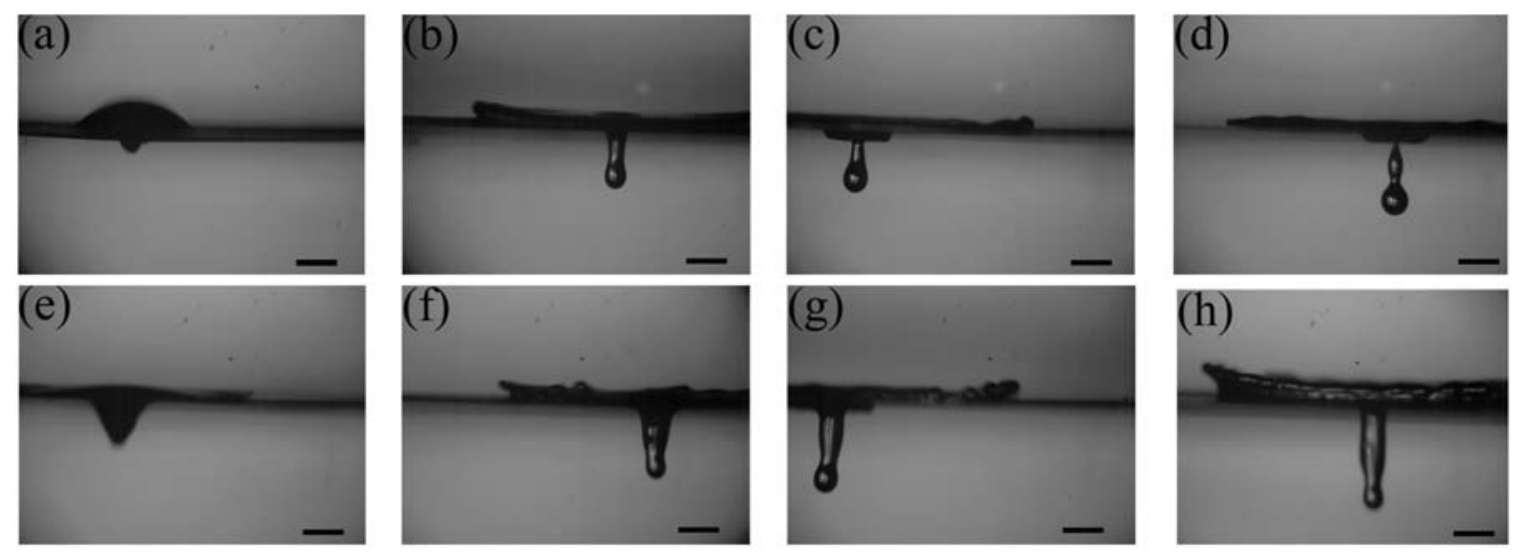

Fig. 3 Water drop images on bare Nylon grids in $2 \mathrm{~ms}$ after the impacts. The impact velocities:

(a) $2.23 \mathrm{~m} / \mathrm{s}$, (b) $2.44 \mathrm{~m} / \mathrm{s}$, (c) $2.64 \mathrm{~m} / \mathrm{s}$, (d) $2.82 \mathrm{~m} / \mathrm{s}$, (e) $3.0 \mathrm{~m} / \mathrm{s}$, (f) $3.16 \mathrm{~m} / \mathrm{s}$, , (g) $3.31 \mathrm{~m} / \mathrm{s}$ and (h) $3.46 \mathrm{~m} / \mathrm{s}$. Scale bars, $1 \mathrm{~mm}$. 

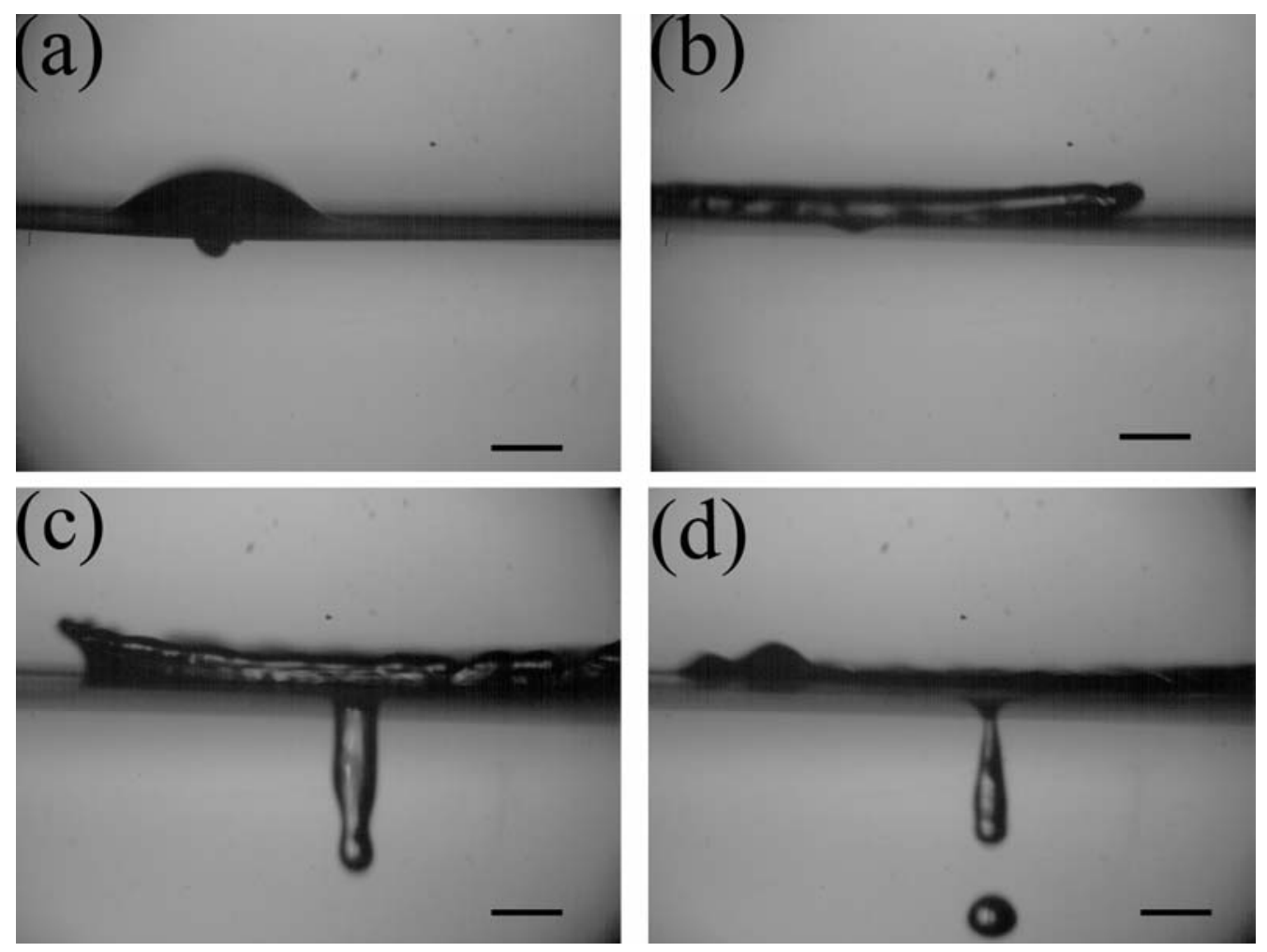

Fig. 4 Water drop impact with the impact velocity of $2.23 \mathrm{~m} / \mathrm{s}$ at the time moments: (a) $\mathrm{t}=2 \mathrm{~ms}$ and (b) $\mathrm{t}=4 \mathrm{~ms}$. Water drop impact with the impact velocity of $3.46 \mathrm{~m} / \mathrm{s}$ at the time moments: (c) $t=2 \mathrm{~ms}$ and (d) $\mathrm{t}=4 \mathrm{~ms}$. The comparison of panels (a) and (c) shows how the amount of water penetrating through Nylon grid increases with an increase in the impact velocity. Panel (b) show that at a lower impact velocity, the surface tension is capable to retract almost all penetrated water, whereas panel (d) shows that at a higher impact velocity, the surface tension is incapable to prevent full penetration of a significant part of the impacting drop. Scale bars, $1 \mathrm{~mm}$.

\subsection{Water Drop Impacts onto Teflon-coated Nylon Grids}

The SEM image of a Teflon-coated Nylon grid is shown in Fig. S1b in ESI. Even though the grid has some blocked pores (the white areas) due to a thin clogging film of Teflon, the occurrence of such blockage was very rare. The majority of the pores are always open (the dark 
areas). Generally, the dip coating of Teflon over Nylon grids was successfully conducted without pore blockage.

The difference in wettability of bare Nylon grids and Teflon-coated Nylon grids was evaluated as follows. Water drops were gently put on each of these two types of grids at different places, and their contact angles observed. Two representative images are depicted in Fig. S2 in ESI. It is seen that bare Nylon grids were partially wettable with water, with the static contact angle varying in the range of $55^{\circ}-65^{\circ}$. On the other hand, the Teflon-coated Nylon grids were rather non-wettable, with the static contact angle varying in the range of $125^{\circ}-140^{\circ}$.

The low velocity $(1 \mathrm{~m} / \mathrm{s})$ impact of a water drop dripped onto a Teflon-coated Nylon grid is shown in Fig. 5. It is seen that after an initial spreading, water drop recedes under the action of surface tension and even tends to bounce back from the grid, albeit the lower part of it remains in contact. No visible water penetration through such grids was found at such low impact velocities (up to $2.44 \mathrm{~m} / \mathrm{s}$ ). This is different from the observations described in the previous subsection for bare Nylon grids. However, for drop impact with the impact velocities of $2.64 \mathrm{~m} / \mathrm{s}$ and beyond, there is visible penetration to the other side of the Teflon-coated Nylon grids resembling that for bare Nylon grids (Fig. 6). Sometimes, it was found that the upper part of penetrating water drop splashes and breaks up into smaller drops, as is characteristic of receding splashes on hydrophobic surfaces ${ }^{19}$. Still, a part of the penetrated drop (the impact velocity of $2.64 \mathrm{~m} / \mathrm{s}$ ) can be lifted back to the rear side of Teflon-coated Nylon grid due to the surface tension effect (Fig. $7 \mathrm{a} \& b)$. For drop impacts with the impact velocity of $3.46 \mathrm{~m} / \mathrm{s}$ onto Teflon-coated Nylon grid, no "lift-up" was found and some part of the penetrated drop detached from the parent drop (Fig. 7) similar to the higher-speed impacts onto bare Nylon grids (Fig. 4d). 

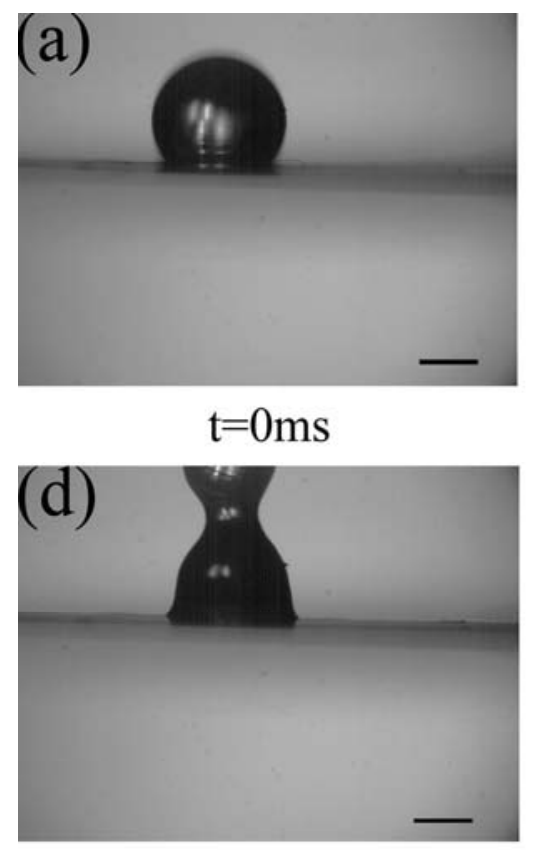

$\mathrm{t}=12 \mathrm{~ms}$

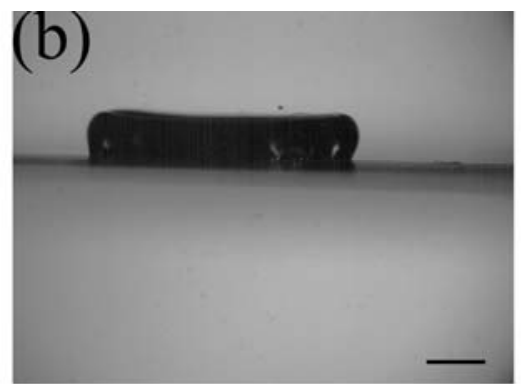

$\mathrm{t}=4 \mathrm{~ms}$

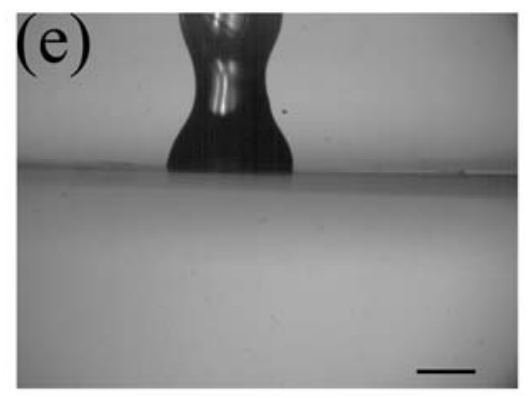

$\mathrm{t}=16 \mathrm{~ms}$

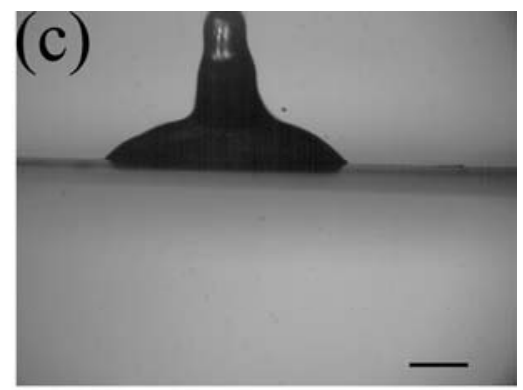

$\mathrm{t}=8 \mathrm{~ms}$

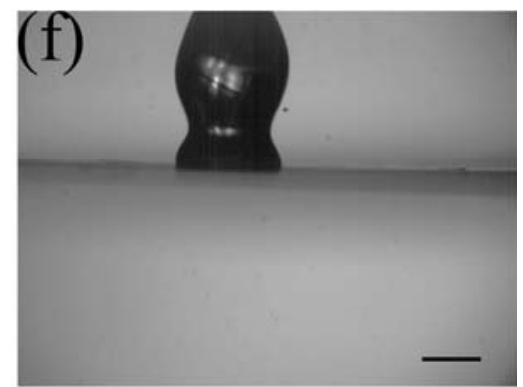

$\mathrm{t}=20 \mathrm{~ms}$

Fig. 5 Water drop impact onto Teflon-coated Nylon grid with a low impact velocity of $1 \mathrm{~m} / \mathrm{s}$ at (a) $\mathrm{t}=0 \mathrm{~ms}$, (b) $\mathrm{t}=4 \mathrm{~ms}$, (c) $\mathrm{t}=8 \mathrm{~ms}$, (d) $\mathrm{t}=12 \mathrm{~ms}$, (e) $\mathrm{t}=16 \mathrm{~ms}$ and (f) $\mathrm{t}=20 \mathrm{~ms}$. Scale bars, $1 \mathrm{~mm}$.
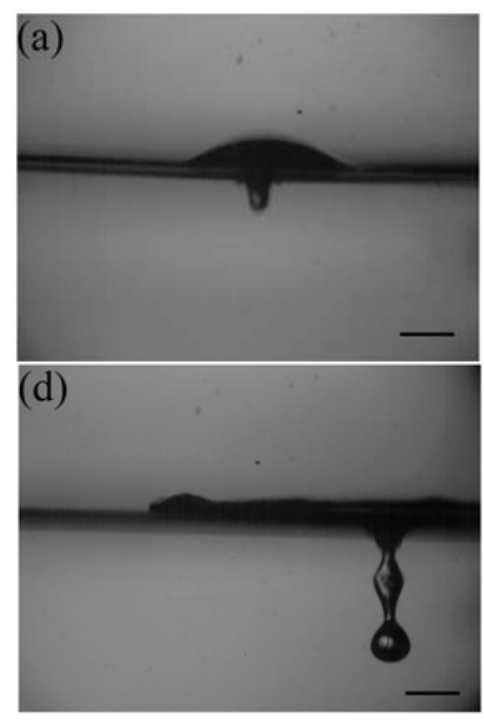
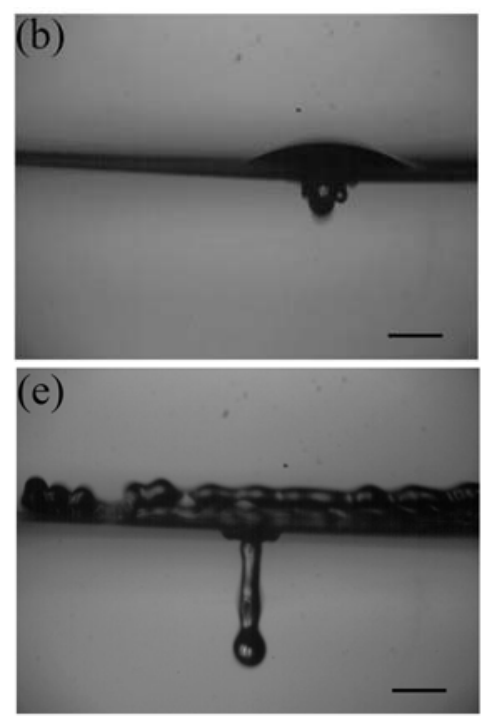
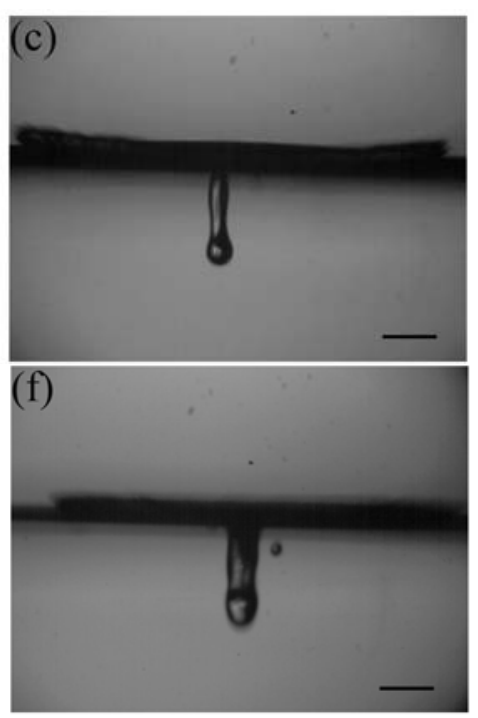

Fig. 6 Water drop impact onto Teflon-coated Nylon grid $2 \mathrm{~ms}$ after the first contact. The impacts velocities of (a) $2.64 \mathrm{~m} / \mathrm{s}$, (b) $2.82 \mathrm{~m} / \mathrm{s}$, (c) $3.0 \mathrm{~m} / \mathrm{s}$, (d) $3.16 \mathrm{~m} / \mathrm{s}$, (e) $3.31 \mathrm{~m} / \mathrm{s}$ and (f) $3.46 \mathrm{~m} / \mathrm{s}$. Scale bars, $1 \mathrm{~mm}$. 

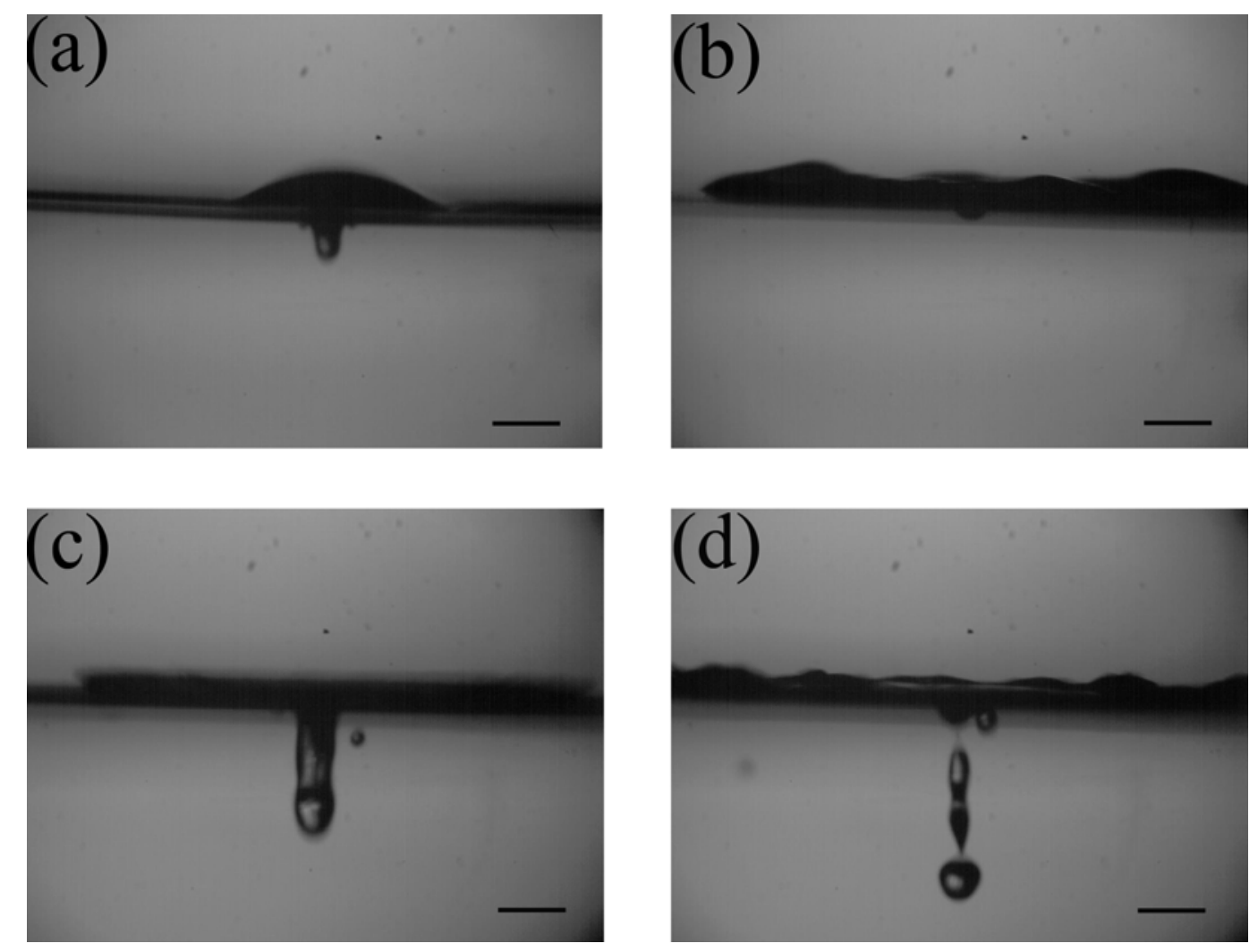

Fig. 7 Water drop impact onto Teflon-coated Nylon grid with the impact velocity of $2.64 \mathrm{~m} / \mathrm{s}$ at (a) $t=2 \mathrm{~ms}$ and (b) $\mathrm{t}=8 \mathrm{~ms}$. An impact with the impact velocity of $3.46 \mathrm{~m} / \mathrm{s}$ at (c) $\mathrm{t}=2 \mathrm{~ms}$ and (d) $t=4 \mathrm{~ms}$. The comparison of panels (a) and (c) shows how the amount of water penetrating through the grid increases with the increase in the impact velocity. Panel (b) shows that at a lower velocity, surface tension is capable to stop and uplift almost all the penetrated water behind the rear side of the grid. On the other hand, panel (d) shows that at a higher impact velocity no "lift-up" is possible anymore and a significant part of water fully detaches from the rear side of the grid. Scale bars, $1 \mathrm{~mm}$.

The inspection of the images in Fig. 2-4 and 6-7 shows that penetrating water jets have diameters of about 0.01 to $0.05 \mathrm{~cm}$. Given the distance of about $30 \mu \mathrm{m}$ between the pores in the 
grid, these values recast into simultaneous penetration of water through $10-250$ pores. Volume fractions of the impacting drops which penetrate through the grid were evaluated using images taken $2 \mathrm{~ms}$ after the impact. It was assumed that water visible below the rear surface of the grid forms a body of revolution, which allows the evaluation of volume fraction based on twodimensional images. Figure 8 shows the penetrated fraction of water drop versus the impact velocity of the initial drop for the two cases: bare Nylon grids and Teflon-coated Nylon grids. It is instructive to see that at lower impact velocities the Teflon coating diminishes the penetrated volume fraction. However, as the impact velocity increases up to $3.31 \mathrm{~m} / \mathrm{s}$, the penetrated volume fractions in both cases (bare Nylon grid and Teflon-coated grid) becomes the same, and the grid wettability has no effect on the penetration process. At higher impact velocities penetration becomes fully dynamic, as predicted in Ref. 15 and 17 . 


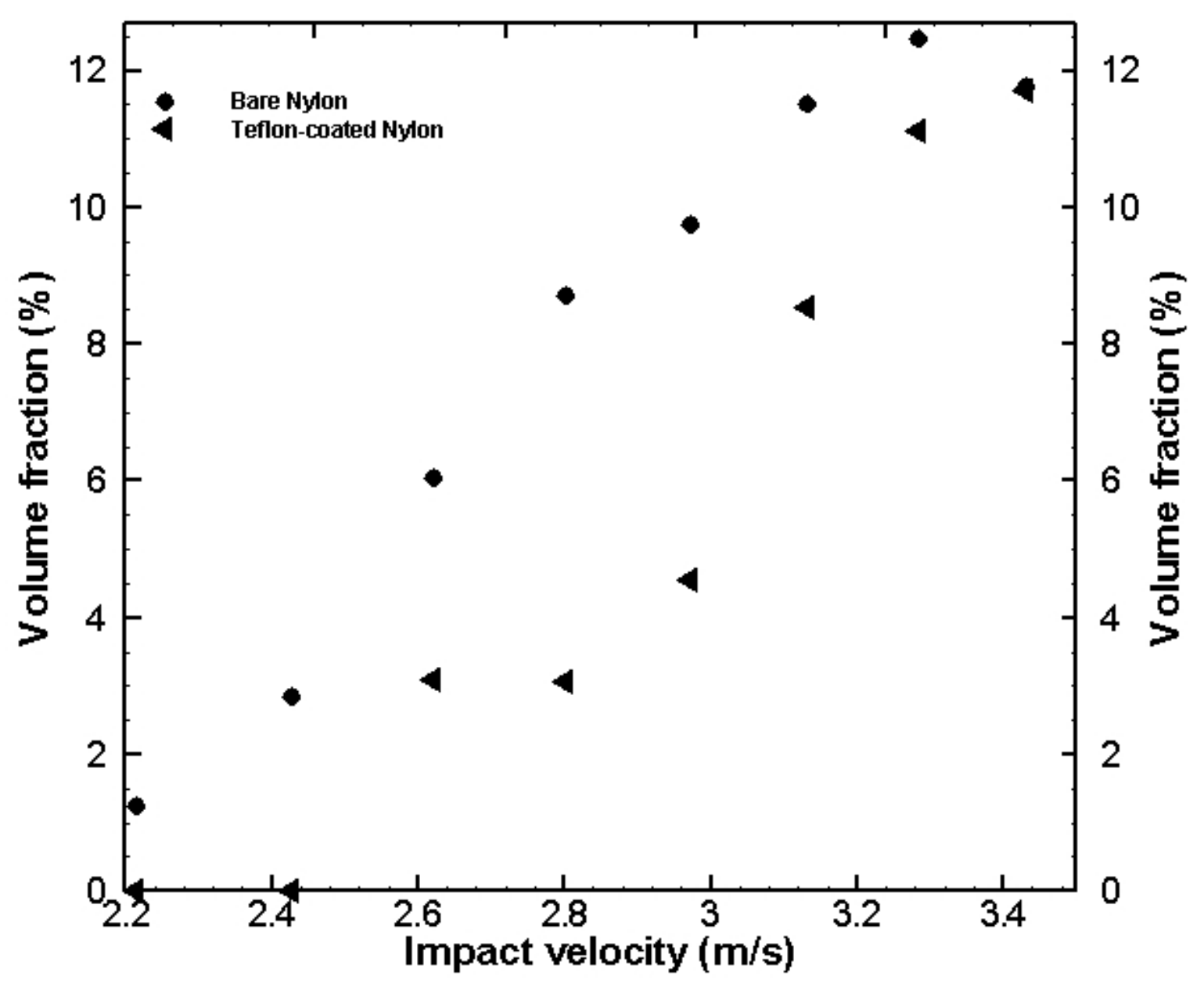

Fig. 8 Fraction of water drops which penetrated through micropores after drop impact onto bare Nylon or Teflon-coated Nylon grids. The data was obtained using the images recorded $2 \mathrm{~ms}$ after drop impact. In the case of Nylon grids, there is no water penetration at the impact velocities below $2.23 \mathrm{~m} / \mathrm{s}$, in the case of Teflon-coated Nylon grids there is no water penetration at the impact velocities below $2.64 \mathrm{~m} / \mathrm{s}$.

3.3 FC 7500 Drop Impacts onto Bare Nylon Grids and Grids Coated with Teflon 
Figure 9 shows the sequence of images for the drop of FC 7500 (in Refs. 32-34 its surface tension and kinematic viscosity are given as $16 \mathrm{mN} / \mathrm{m}$ and $0.77 \mathrm{cSt}$, respectively) for the impact velocity of $1 \mathrm{~m} / \mathrm{s}$ onto a bare Nylon grid. It can be seen that the liquid penetrates through the grid even at such a low impact velocity (compared with the threshold velocity of $2.23 \mathrm{~m} / \mathrm{s}$ for water penetration through such grids). This can be attributed to the fact that for the penetration through a nanofiber mat of thickness $h$, the impact velocity needed for the full penetration is of the order of $\mathrm{V}=v \mathrm{~h} / \delta^{2}$ (cf. the theoretical section 4), where $v$ is the kinematic viscosity and $\delta$ is the pore size. An impact with such velocity can overbear viscous dissipation in the pores and deliver the liquid entering the pores to the rear side of the grid. The kinematic viscosity of FC 7500 is $0.77 \mathrm{cSt}$, which is less than that of water, which explains the reason for easier penetration of FC 7500 (compared to that of water) through the entire nanofiber mat thickness at lower impacting velocities.

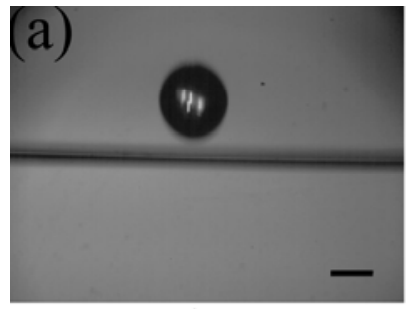

$\mathrm{t}=0 \mathrm{~ms}$

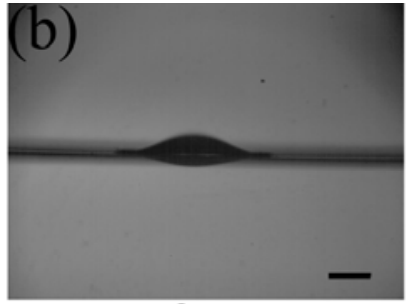

$\mathrm{t}=2 \mathrm{~ms}$

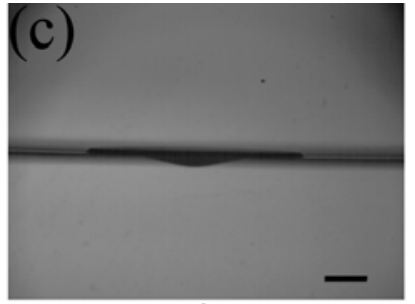

$\mathrm{t}=4 \mathrm{~ms}$

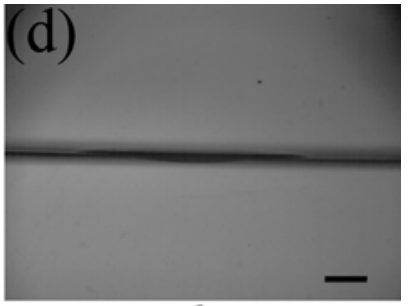

$\mathrm{t}=6 \mathrm{~ms}$

Fig. 9 Drop of FC 7500 impacting onto a bare Nylon grid with the impact velocity of $1 \mathrm{~m} / \mathrm{s}$ at (a) $\mathrm{t}=0 \mathrm{~ms},(\mathrm{~b}) \mathrm{t}=2 \mathrm{~ms},(\mathrm{c}) \mathrm{t}=4 \mathrm{~ms},(\mathrm{~d}) \mathrm{t}=6 \mathrm{~ms}$ after the impact. Scale bars, $1 \mathrm{~mm}$.

An important observation can be made for impacts of FC 7500 drops onto bare Nylon grids. At a certain threshold velocity of about $2 \mathrm{~m} / \mathrm{s}, \mathrm{FC} 7500$ had started to emerge after 
penetration as separate tiny jets originating from the pores of the Nylon grid, as seen in Fig. 10a. The leading parts of these tiny jets then break up into tiny droplets (presumably due to the Rayleigh capillary instability), whereas the residual parts then coalesce to form a single jet, similar to the one accompanying water drop impact, as can be seen in Fig. 10b-c. The merger jet, in its turn, breaks into bigger secondary droplets, again due to the action of surface tension (the capillary instability).
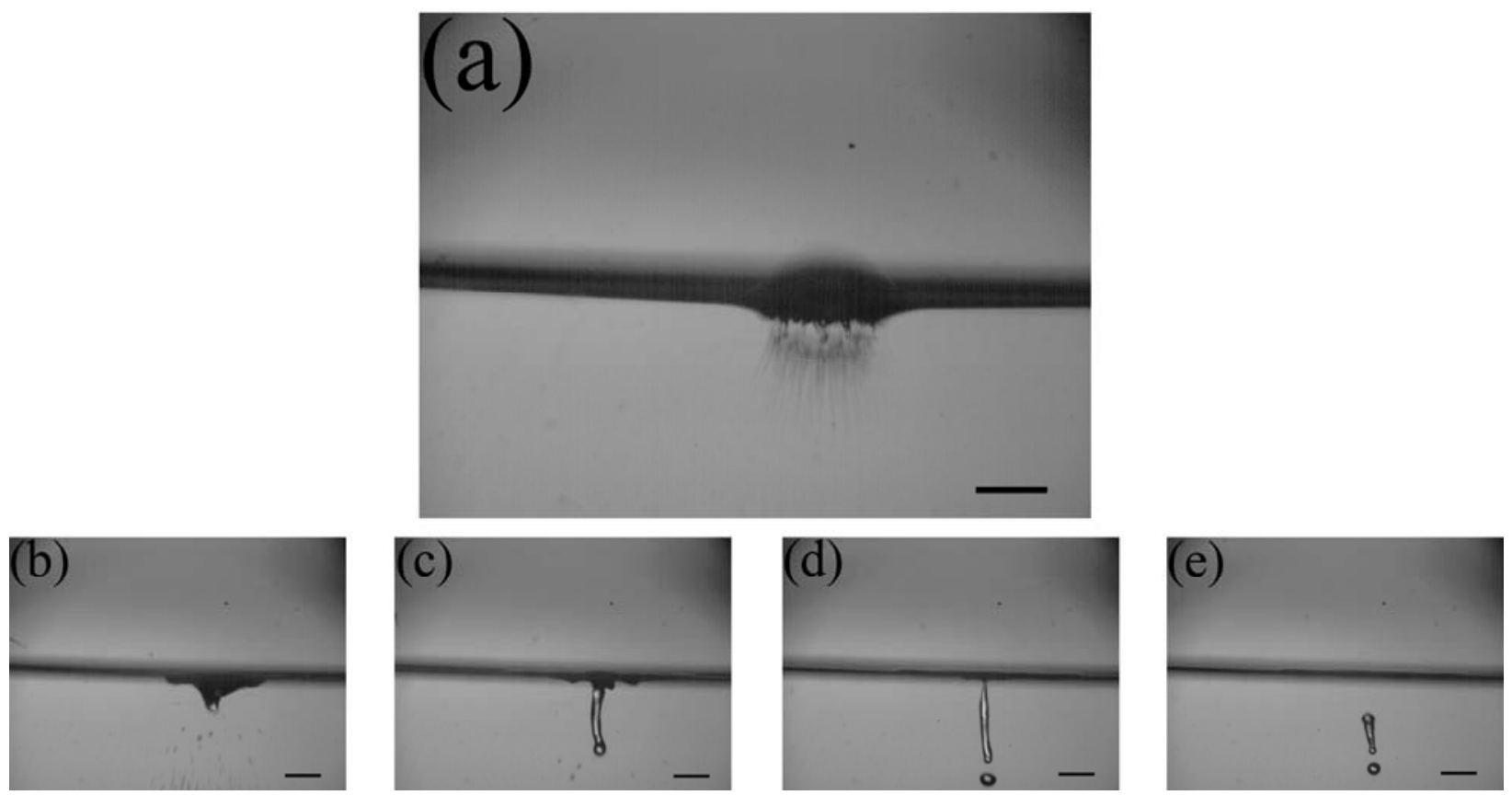

Fig. 10 Drop of FC 7500 impacting onto a bare Nylon grid with the impact velocity of $2.64 \mathrm{~m} / \mathrm{s}$. Scale bars, $1 \mathrm{~mm}$.

Figure 11 shows the sequence of images for the FC 7500 drop impact with the impact velocity of $3.46 \mathrm{~m} / \mathrm{s}$. The appearance of tiny jets is also apparent in this case: $\mathrm{cf}$. Fig. 11 which depicts the processes of penetration, coalescence and jet breakup similar to those of Fig. 10. The tiny jets are rather blurred in Fig. 11a, which is due to the high impact speed of the drop. 


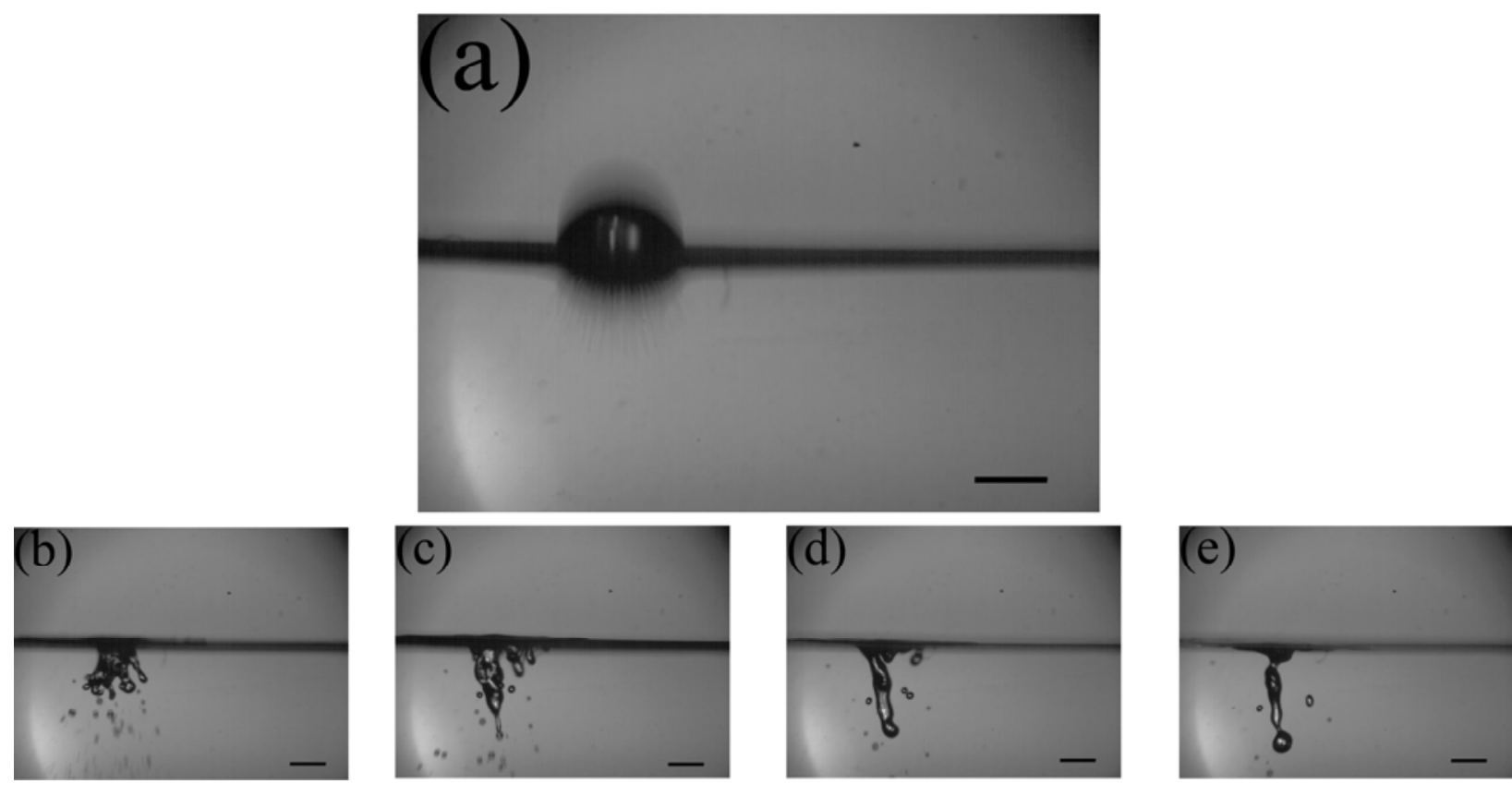

Fig. 11 Impact of FC 7500 drop onto bare Nylon grid with the impact velocity of $3.46 \mathrm{~m} / \mathrm{s}$. Scale bars, $1 \mathrm{~mm}$.

The effect of the impact height on the outcome of the FC 7500 drop impact is illustrated in Fig. 12. The penetration patterns for this liquid corresponding to various heights can be clearly distinguished. 

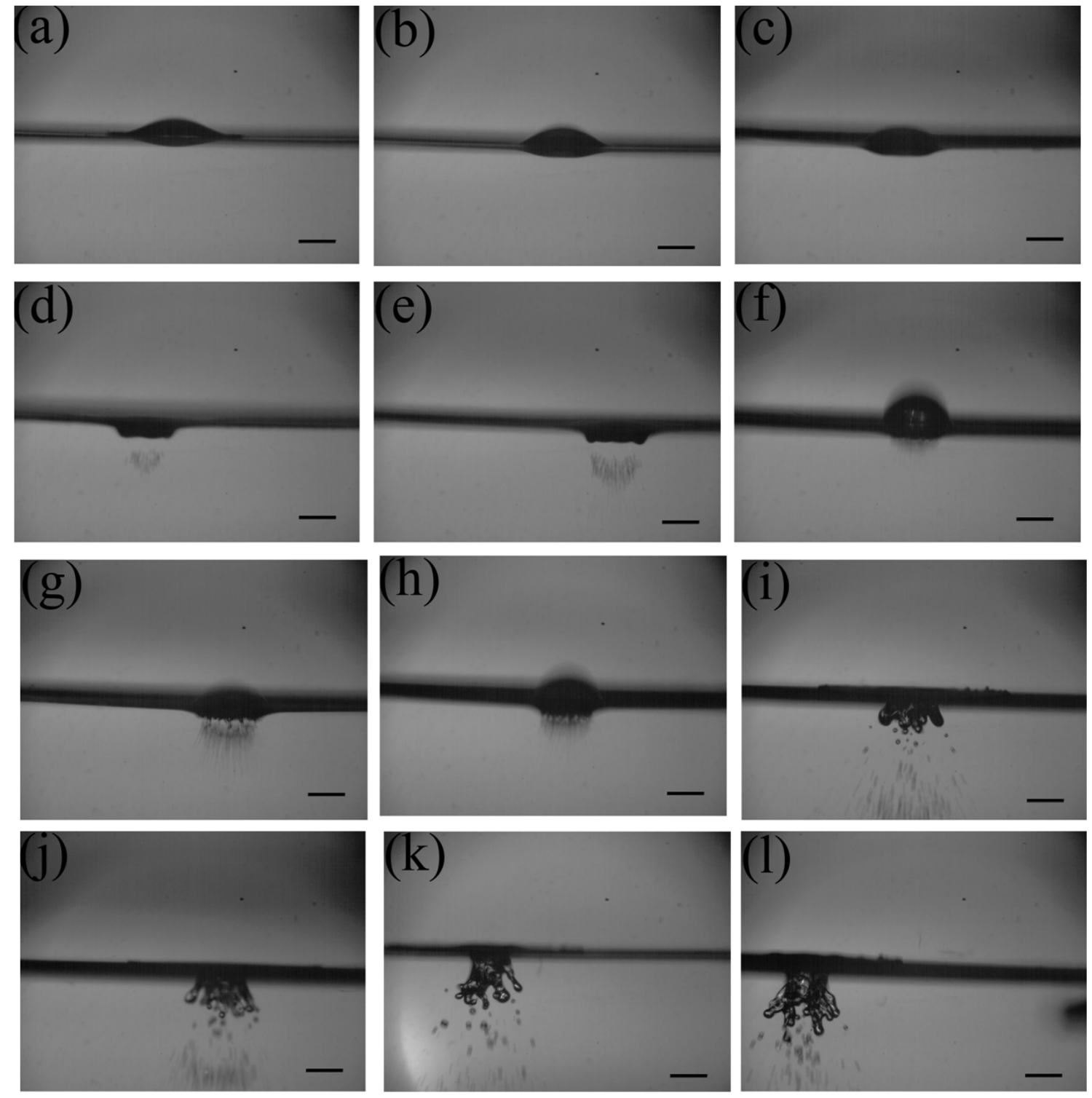

Fig. 12 Effect of the impact height on the penetration pattern of drops of FC 7500 liquid impacting onto bare Nylon grid. The impact velocities: (a) $1.0 \mathrm{~m} / \mathrm{s}$, (b) $1.41 \mathrm{~m} / \mathrm{s}$, (c) $1.73 \mathrm{~m} / \mathrm{s}$, (d) $2.0 \mathrm{~m} / \mathrm{s}$, (e) $2.23 \mathrm{~m} / \mathrm{s}$, (f) $2.44 \mathrm{~m} / \mathrm{s}$, (g) $2.64 \mathrm{~m} / \mathrm{s}$, (h) $2.82 \mathrm{~m} / \mathrm{s}$, (i) $3.0 \mathrm{~m} / \mathrm{s}$, (j) $3.16 \mathrm{~m} / \mathrm{s}$, (k) 3.31 $\mathrm{m} / \mathrm{s}$ and (1) $3.46 \mathrm{~m} / \mathrm{s}$. All the images correspond to $2 \mathrm{~ms}$ after drop impact. Scale bars, $1 \mathrm{~mm}$.

Similar experiments were conducted with the FC 7500 drop impacts onto Teflon-coated Nylon grids. The experiments showed no visible difference in the penetration pattern of drops of 
FC 7500 through Teflon-coated grids compared to those for the bare Nylon grids. Figure S3 in ESI shows (in comparison with Fig. 12) that the presence of the Teflon coating on the grid practically does not affect the FC 7500 penetration process after drop impact.

\subsection{Drop Impact of Hexane Drops onto Bare Nylon Grids and Grids Coated with Teflon}

Hexane has a kinematic viscosity of $0.45 \mathrm{cSt}$, which is even lower than that of FC 7500 . The results for the hexane drop impacts onto bare Nylon grid are shown in Fig. 13 for three impact velocity values: $\mathrm{V}=1 \mathrm{~m} / \mathrm{s}, \mathrm{V}=1.4 \mathrm{~m} / \mathrm{s}$, and $\mathrm{V}=3.46 \mathrm{~m} / \mathrm{s}$. It is seen that hexane drops fully penetrate through bare Nylon grids at very low velocity of $1 \mathrm{~m} / \mathrm{s}$ compared to that of water drops for which the first penetration was observed at $2.23 \mathrm{~m} / \mathrm{s}$. This can be attributed to a much lower kinematic viscosity of hexane, and thus the reduced dissipation of kinetic energy inside pores. After penetrating at the impact speed of $1 \mathrm{~m} / \mathrm{s}$, hexane blob retracts back to the rear surface of Nylon grid under the action of surface tension. Hexane drop impact at high speed of $3.46 \mathrm{~m} / \mathrm{s}$ results in separate jets coming out of several micropores of the Nylon grid as is seen in

Fig. 13. The relatively low surface tension of hexane $(18.43 \mathrm{mN} / \mathrm{m})$ compared to that of water is insufficient to merge the multiple jets after penetration (cf. Fig. 13 and 3). 


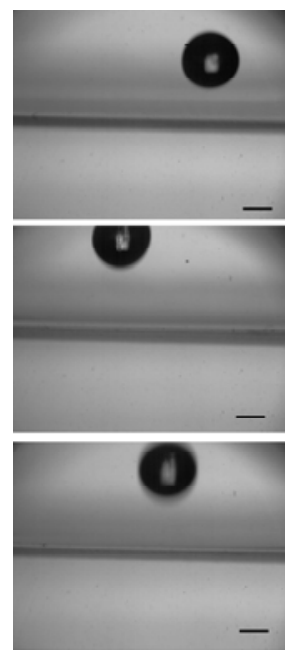

$\mathrm{t}=0 \mathrm{~ms}$
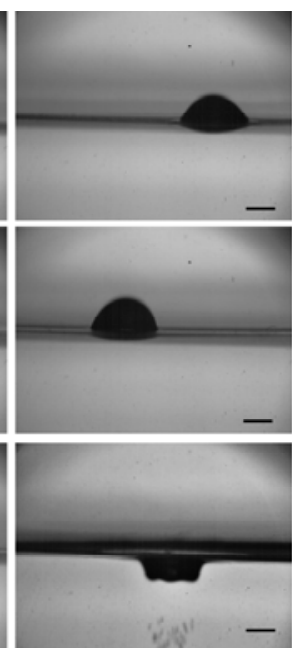

$\mathrm{t}=2 \mathrm{~ms}$

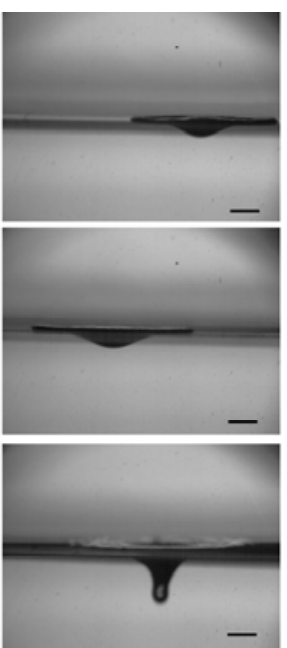

$\mathrm{t}=4 \mathrm{~ms}$

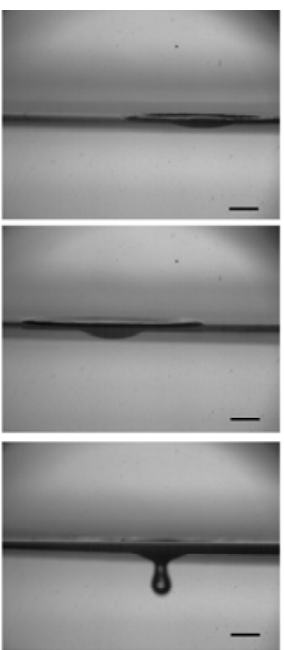

$\mathrm{t}=6 \mathrm{~ms}$
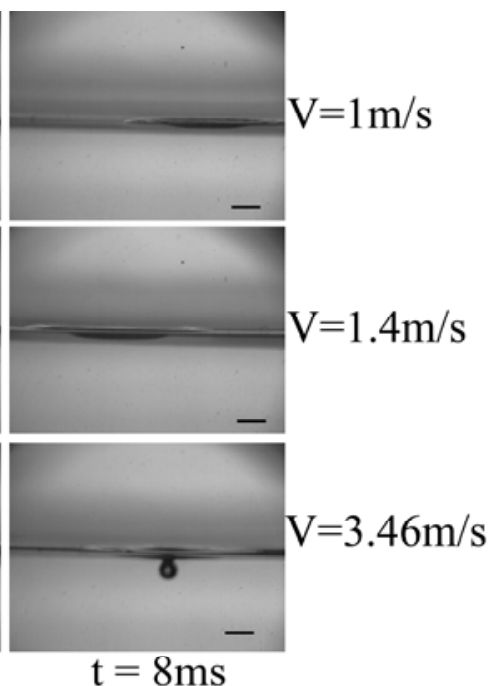

Fig. 13 Hexane drop impact onto bare Nylon grid at different impact velocities. The sequence of the images for each velocity value corresponds to the time span from $0 \mathrm{~ms}$ (the moment just before the impact) to $8 \mathrm{~ms}$. Scale bars, $1 \mathrm{~mm}$.

The impact of hexane drops onto Teflon-coated Nylon grid at low and high impact velocity $(\mathrm{V}=1 \mathrm{~m} / \mathrm{s}$ and $\mathrm{V}=3.46 \mathrm{~m} / \mathrm{s}$, respectively) are depicted in Fig. 14. The outcomes look similar to those for bare Nylon grid. At low velocity a blob which penetrated through the grid retracts back to the rear surface, whereas at high impact velocity separate jets are visible behind the Nylon grid.

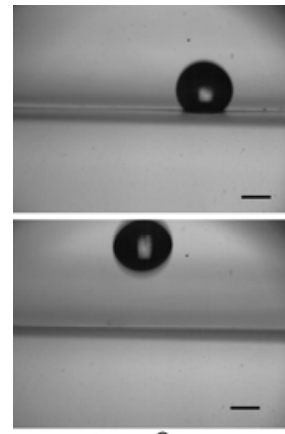

$\mathrm{t}=0 \mathrm{~ms}$

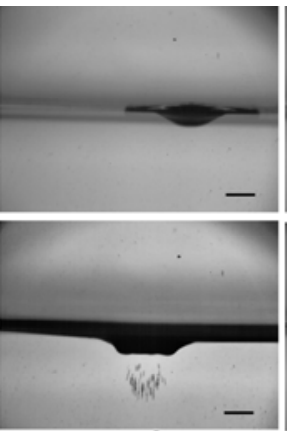

$\mathrm{t}=2 \mathrm{~ms}$

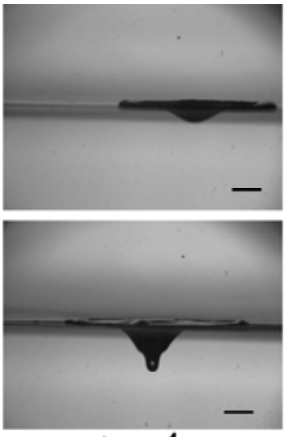

$\mathrm{t}=4 \mathrm{~ms}$

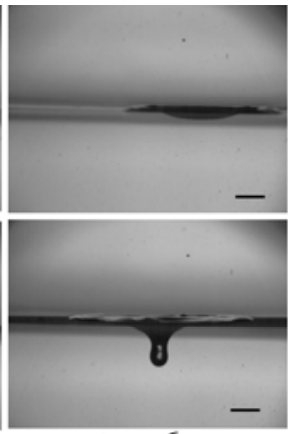

$\mathrm{t}=6 \mathrm{~ms}$

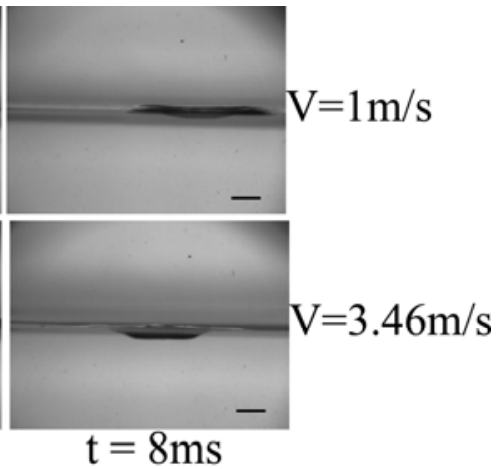


Fig. 14 Hexane drop impact onto Teflon-coated Nylon grid at the impact velocities of $\mathrm{V}=1 \mathrm{~m} / \mathrm{s}$ and $\mathrm{V}=3.46 \mathrm{~m} / \mathrm{s}$. Scale bars, $1 \mathrm{~mm}$.

The results for the FC 7500 and hexane drops show that tiny jets behind the grid break into tiny secondary droplets presumably due to the capillary instability. That makes it extremely difficult to evaluate the amount of liquid penetrated through the grid. Therefore, the results similar to those for water in Fig. 8 are unavailable for FC 7500 and hexane. It is emphasized that for both these low surface tension and low viscosity liquids, FC 7500 and hexane, penetration through pores was much easier (at a lower impact velocity) than that for water. Therefore, the experiments described in the following subsections were conducted for water drops alone.

\subsection{Drop Impact onto Electrospun PAN Nanofiber Mats Supported by Bare Nylon Grids}

An $8 \mathrm{wt} \%$ PAN solution in DMF was electrospun onto bare Nylon grids for different times. A representative SEM image of PAN nanofiber mat on a grid is shown in Fig. S4 in ESI. Figure S4a in ESI shows the overall view, whereas Fig. S4b in ESI shows a zoomed-in image of the PAN nanofibers suspended over the grid openings. It can be seen that due to the presence of nanofibers, the pore sizes are reduced to the order of 1-10 $\mu \mathrm{m}$. It is emphasized that the pore size and the thickness of the nanofiber mat are determined by the duration of electrospinning (see Fig. S5 in ESI) and the relative humidity of the surrounding atmosphere. During electrospinning of PAN nanofiber mats onto bare Nylon grids the relative humidity was within the range of $20-30 \%$ and the electrospinning duration was from 5 to $60 \mathrm{~s}$. The thickness of the deposited PAN nanofiber mats was measured using the Olympus BX-51 Optical Microscope. The microscope was focused at the bottom layer of nanofibers, and after that, on the top layer. The difference 
between the corresponding two focus lengths was attributed to the mat thickness (Fig. S6 in ESI). It can be seen from Fig. S6 in ESI that the fiber mat thickness does not possess any visible trend versus the deposition time. However, it was observed that while the mat thickness can stay constant or even decrease, the pore size decreases at longer deposition times, indicating a more dense packing of nanofibers (see Fig. S5 in ESI). It should also be mentioned that attempts were made to measure the pore size of nanofiber mats deposited onto bare Nylon grids by using mercury porosimetry. However, the results reflected only the pore size of about $20 \mu \mathrm{m}$, whereas Fig. S4 in ESI shows that the pore size is in the range of 1-10 $\mu \mathrm{m}$. The disagreement can be attributed to the fact that in such experiments mercury emerged through the Nylon grid, probably after delaminating the more flexible nanofibers, which made mercury porosimetry results unreliable. Therefore, in the discussion below the electrospining time is chosen as the mat characteristics.

Drop impact with the impact velocity of $3.46 \mathrm{~m} / \mathrm{s}$ onto Nylon grids coated with PAN nanofibers electrospun for 5-60 s is shown in the images in Fig. 15. It was found that the threshold velocity for water penetration through the nanofiber-coated Nylon grid (with the mat deposited for $5 \mathrm{~s}$ ) was $2.43 \mathrm{~m} / \mathrm{s}$. This value is higher than that of the corresponding threshold value of $2.23 \mathrm{~m} / \mathrm{s}$ for bare Nylon grids. Therefore, nanofiber mats deposited on Nylon grids significantly reduce permeability. Water penetration through the first layer of pores at the nanofiber mat surface is hardly expected to be diminished by the fact that pores in the mats are an order of magnitude smaller than in bare Nylon grids ${ }^{15}$. However, the presence of nanofibers results in a significant increase in viscous dissipation during water flow inside the pores, as discussed in the theoretical section 4 below. The latter factor determines the thickness of nanofiber mat which can be fully penetrated at a given impact velocity. Alternatively, viscous 
dissipation determines a higher critical impact velocity for a full penetration of a given mat thickness in comparison with that for the bare Nylon grid underneath. It is emphasized that water penetration after drop impact onto a nanofiber mat deposited on a grid is mostly determined by the mat permeability, whereas the grid permeability effect is negligible since the grid is much more permeable than the mat. Indeed, pores in the mat are of the order of 1-10 $\mu \mathrm{m}$ (cf. Fig. S4 in ESI), while those in the grid are of the order of $20 \mu \mathrm{m}$, and the permeability depends on the pore size squared.

Figure 16 depicts the critical height (critical threshold velocity) of drop impact needed for the full water penetration through nanofiber mats on Nylon grid electrospun for different times. The critical height linearly increases with the deposition time in the range studied.

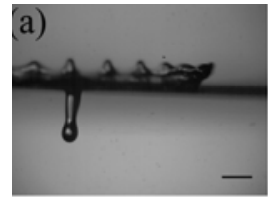

$t=5 s$

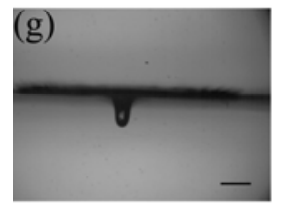

$t=35 \mathrm{~s}$
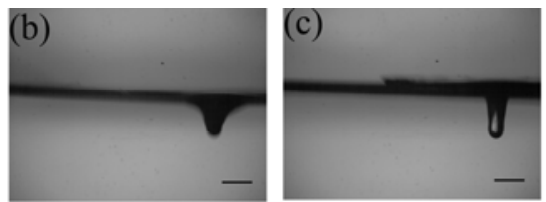

$t=15 \mathrm{~s}$

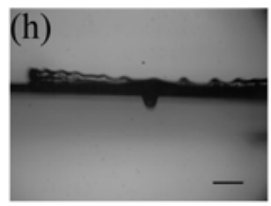

$\mathrm{t}=40 \mathrm{~s}$

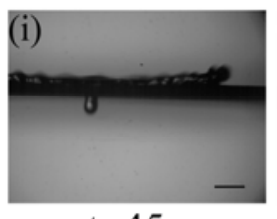

$t=45 \mathrm{~s}$

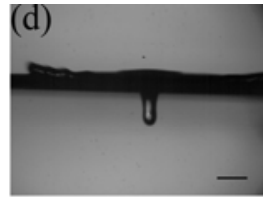

$\mathrm{t}=20 \mathrm{~s}$

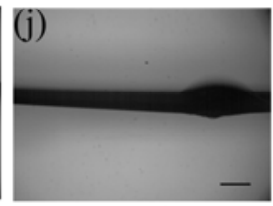

$\mathrm{t}=50 \mathrm{~s}$

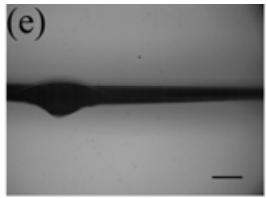

$\mathrm{t}=25 \mathrm{~s}$

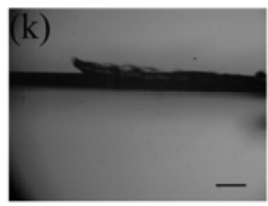

$\mathrm{t}=55 \mathrm{~s}$

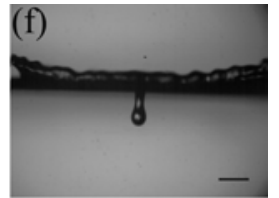

$\mathrm{t}=30 \mathrm{~s}$

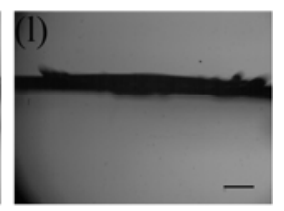

$\mathrm{t}=60 \mathrm{~s}$

Fig. 15 Impacts of the identical water drops onto PAN nanofiber mats electrospun onto Nylon grids for different time t. The impact velocity of $3.46 \mathrm{~m} / \mathrm{s}$, the initial drop diameter was $2 \mathrm{~mm}$. The electrospinning time $t$ values were: (a) $t=5 s$, (b) $t=10 s$, (c) $t=15 s$, (d) $t=20 s$, (e) $t=25 s$, (f) $\mathrm{t}=30 \mathrm{~s},(\mathrm{~g}) \mathrm{t}=35 \mathrm{~s}$, (h) $\mathrm{t}=40 \mathrm{~s}$, (i) $\mathrm{t}=45 \mathrm{~s},(\mathrm{j}) \mathrm{t}=50 \mathrm{~s},(\mathrm{k}) \mathrm{t}=55 \mathrm{~s}$ and (l) $\mathrm{t}=60 \mathrm{~s}$. The images correspond to $2 \mathrm{~ms}$ after the moment when the drops touched the target. Scale bars, $1 \mathrm{~mm}$. 


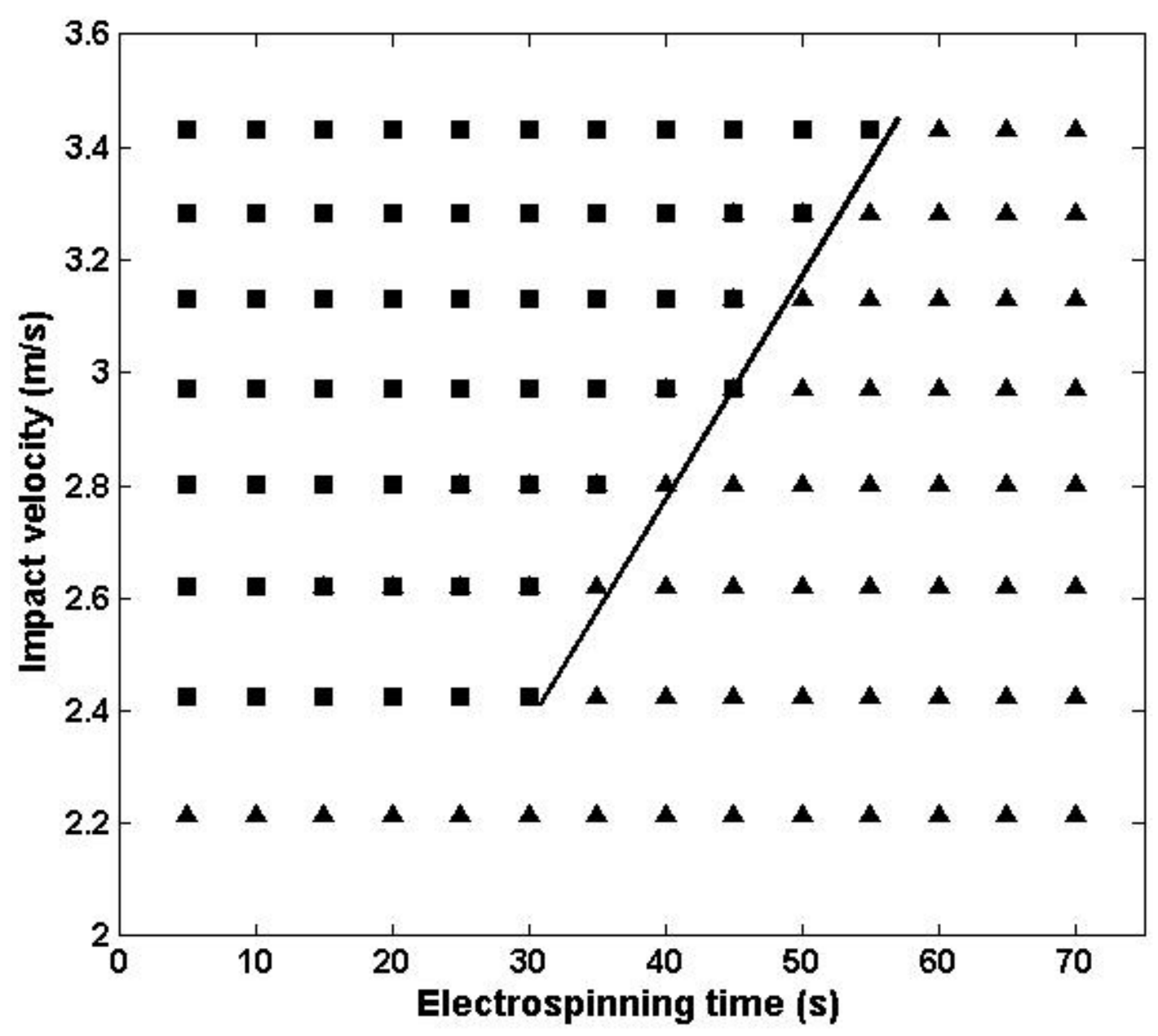

Fig. 16 The critical velocity for water penetration after drop impact versus the electrospinning time of PAN nanofiber mats onto Nylon grids. The square symbols correspond to the experiments where water penetration was observed, whereas the triangular ones correspond to the experiments without water penetration after drop impact. The initial drop diameter was 2 $\mathrm{mm}$.

The nanofiber mats deposited over Nylon grids were inspected before and after drop impacts to corroborate that no big holes in the mats were created by drops, and water penetration was indeed associated with the initial mat porosity. The surface of the nanofiber mat deposited 
over a Nylon grid shown in Fig. S7a in ESI had the average pore size of about $10 \mu \mathrm{m}$. The same location was inspected in Fig. S7b in ESI after drop impact and complete water drying. In the latter case several different nanofiber layers visible in the image look as they were compressed together by drop impact (or water drying). On the other hand, it is also evident that the drop impact did not create any holes in the nanofiber mat as the pore size and the overall mat morphology still remain approximately the same. It is emphasized that the drop was on the scale of $1 \mathrm{~mm}$, and the entire area of the nanofiber mat seen in Fig. S7 was subjected to the impact. In addition, the effect of multiple drop impacts at the same place of nanofiber mats was studied. PAN nanofibers were electrospun on a bare Nylon grid. Then, FC 7300 drops $(\sim 1 \mathrm{~mm}$ in diameter) impacted the same spot with the impact velocity $3.31 \mathrm{~m} / \mathrm{s}$ eight times in succession. The images of the nanofiber mat before the first impact, and after the $4^{\text {th }}, 6^{\text {th }}$ and $8^{\text {th }}$ impacts taken using Olympus BX51 microscope are shown in Figs. S8a-d, respectively, in ESI. It can be

seen from the images that no big holes appear even after the $8^{\text {th }}$ impact, albeit some local nanofiber rearrangement could happen. Note, that FC 7300 possesses a relatively low surface tension, which diminishes nanofiber rearrangement when samples are dried after drop impact prior to the observations.

\subsection{Water Drop Impact onto Electrospun Nylon 6/6 Nanofiber Mats on Bare Nylon Grids}

Nylon 6/6 nanofibers were electrospun over bare Nylon grids for a few seconds. The rate of Nylon 6/6 nanofiber deposition was very rapid compared to that of PAN nanofibers. The accumulation of Nylon 6/6 nanofibers beyond $10 \mathrm{~s}$ would result in very thick nanofiber mats, which exceed the critical nanofiber mat thickness, estimated theoretically (cf. the theoretical part 4) and also significantly reduce the pore size to $2-4 \mu \mathrm{m}$. Therefore, Nylon $6 / 6$ nanofibers were 
collected for $5 \mathrm{~s}$. The thickness of the collected Nylon 6/6 nanofiber mats was in the range of 8$10 \mu \mathrm{m}$. Numerous (10-12) samples of Nylon 6/6 nanofiber mats were collected and used in water drop impact experiments. Figure S9a in ESI shows an SEM image of a bare Nylon grid with electrospun Nylon 6/6 nanofibers supported by it. Figure S9b in ESI shows a zoomed-in image of Nylon 6/6 nanofibers collected over a pore in the Nylon grid. The pore size in the mat is of the order of $1-4 \mu \mathrm{m}$.

Figure 17 shows a sequence of images illustrating water drop impact onto Nylon 6/6 nanofiber mat electrospun over a bare Nylon grid. It is seen that at a low impact velocity the scenario is similar to the impact onto PAN nanofiber mats (cf. Fig. 2), where the water drop spreads after impact and its contact line becomes pinned with no visible penetration through the mat. An increase in the impact velocity to $\mathrm{V}=2.64 \mathrm{~m} / \mathrm{s}$ results in a water drop corona splash after the impact. The wettability of cast PAN and Nylon 6/6 are approximately the same, which is evident from the contact angle measurement results shown in Table 3 and the thickness of these nanofiber mats was also approximately the same. However, full water penetration in the case of Nylon $6 / 6$ begins from the impact velocity of $3 \mathrm{~m} / \mathrm{s}$, compared to the impact velocity of $2.44 \mathrm{~m} / \mathrm{s}$ in the case of PAN. This is attributed to the reduced pore size of the Nylon $6 / 6$ nanofiber mat compared to that of PAN, which results in a higher viscous dissipation of kinetic energy inside the pores in the case of Nylon 6/6. At the impact velocity of $3.46 \mathrm{~m} / \mathrm{s}$ water drop fully penetrates through the Nylon 6/6 nanofiber mat on a bare Nylon grid. The penetrated water drop can either retract back to the rear side of the grid under the action of surface tension, or break off as a merged jet and smaller secondary droplets resulting from the capillary instability. 
(a) $\mathrm{V}=1 \mathrm{~m} / \mathrm{s}$

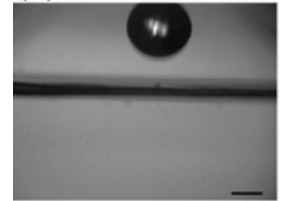

$\mathrm{t}=0 \mathrm{~ms}$

(b) $\mathrm{V}=2.64 \mathrm{~m} / \mathrm{s}$

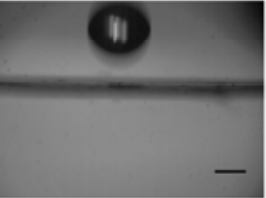

$\mathrm{t}=0 \mathrm{~ms}$

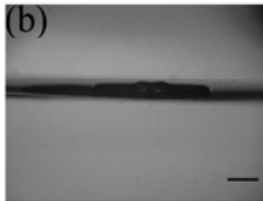

$\mathrm{t}=4 \mathrm{~ms}$

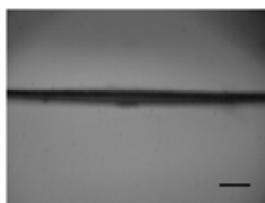

$\mathrm{t}=2 \mathrm{~ms}$

(c) $\mathrm{V}=3.46 \mathrm{~m} / \mathrm{s}$

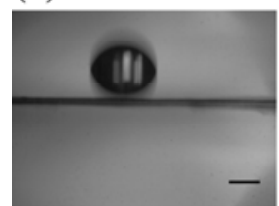

$\mathrm{t}=0 \mathrm{~ms}$

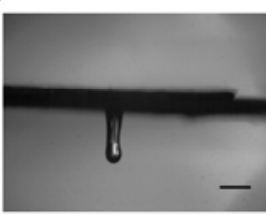

$\mathrm{t}=2 \mathrm{~ms}$

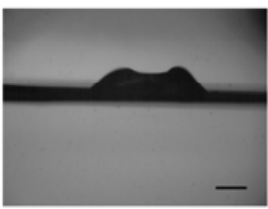

$\mathrm{t}=8 \mathrm{~ms}$

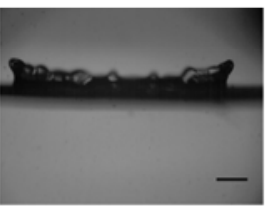

$\mathrm{t}=4 \mathrm{~ms}$

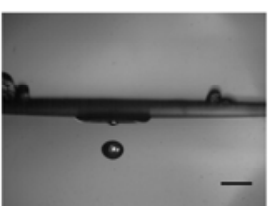

$\mathrm{t}=4 \mathrm{~ms}$

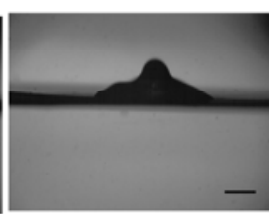

$\mathrm{t}=12 \mathrm{~ms}$

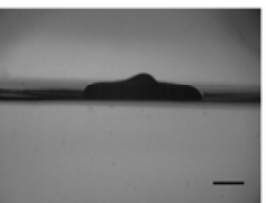

$\mathrm{t}=16 \mathrm{~ms}$
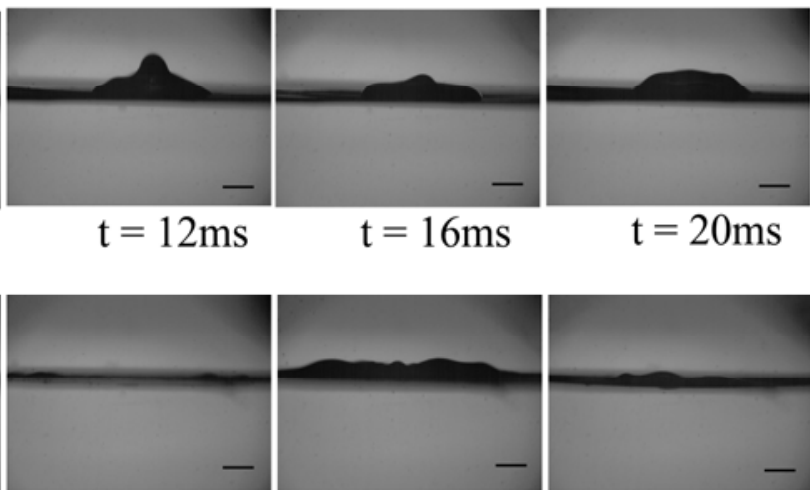

$\mathrm{t}=6 \mathrm{~ms}$

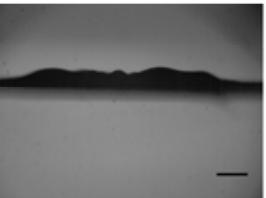

$\mathrm{t}=8 \mathrm{~ms}$

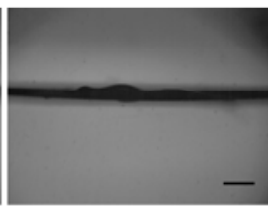

$\mathrm{t}=10 \mathrm{~ms}$

Fig. 17 Water drop impact onto electrospun Nylon 6/6 nanofiber mats on a bare Nylon grid at different velocities: (a) $\mathrm{V}=1 \mathrm{~m} / \mathrm{s}$, (b) $\mathrm{V}=2.64 \mathrm{~m} / \mathrm{s}$ and (c) $\mathrm{V}=3.46 \mathrm{~m} / \mathrm{s}$. The images correspond to different time instants from the moment of impact (approximately at $\mathrm{t}=0 \mathrm{~ms}$ ). Scale bars, $1 \mathrm{~mm}$.

\subsection{Water Drop Impact onto Electrospun PCL Nanofiber Mats Supported on Bare Nylon} grids

PCL nanofibers were electrospun onto bare Nylon grids for different times in the range of 10 to $120 \mathrm{~s}$. These supported nanofiber mats were subjected to water drop impacts with velocities in the range $1 \mathrm{~m} / \mathrm{s}$ to $3.46 \mathrm{~m} / \mathrm{s}$. As it was mentioned before, deposition of PAN nanofibers onto bare Nylon grids was dependent on the relative humidity in the surrounding air. During electrospinning of PCL nanofibers the relative humidity was within the range of $50-60 \%$, which is higher than that for the PAN nanofibers discussed above (20-30\%). Therefore, for the sake of 
comparison with PCL, electrospun PAN nanofiber mats were also prepared at the higher humidity and with the thicknesses and pore sizes comparable to those of the electrospun PCL mats. The penetration charts for both PAN and PCL nanofiber mats obtained in the water drop impact experiments were superimposed and presented in Fig. 18. Each point in the penetration chart corresponds to a certain combination of the impact velocity and the electrospinning time. The square symbols correspond to the penetration events, whereas the triangular symbols correspond to the non-penetration ones (for PCL nanofibers). The threshold velocity corresponding to the same time of deposition during electrospinning, appears to be different for PAN and PCL. Namely it is higher for PCL mats compared to that for PAN. This can be attributed to the interplay of the difference in the thickness and different pore sizes in the mats, and different wettability of PCL and PAN (much lower for the former). However, the penetration chart in Fig. 18 shows that for any wettability, after a threshold velocity is surpassed, water penetration inevitably happens. 


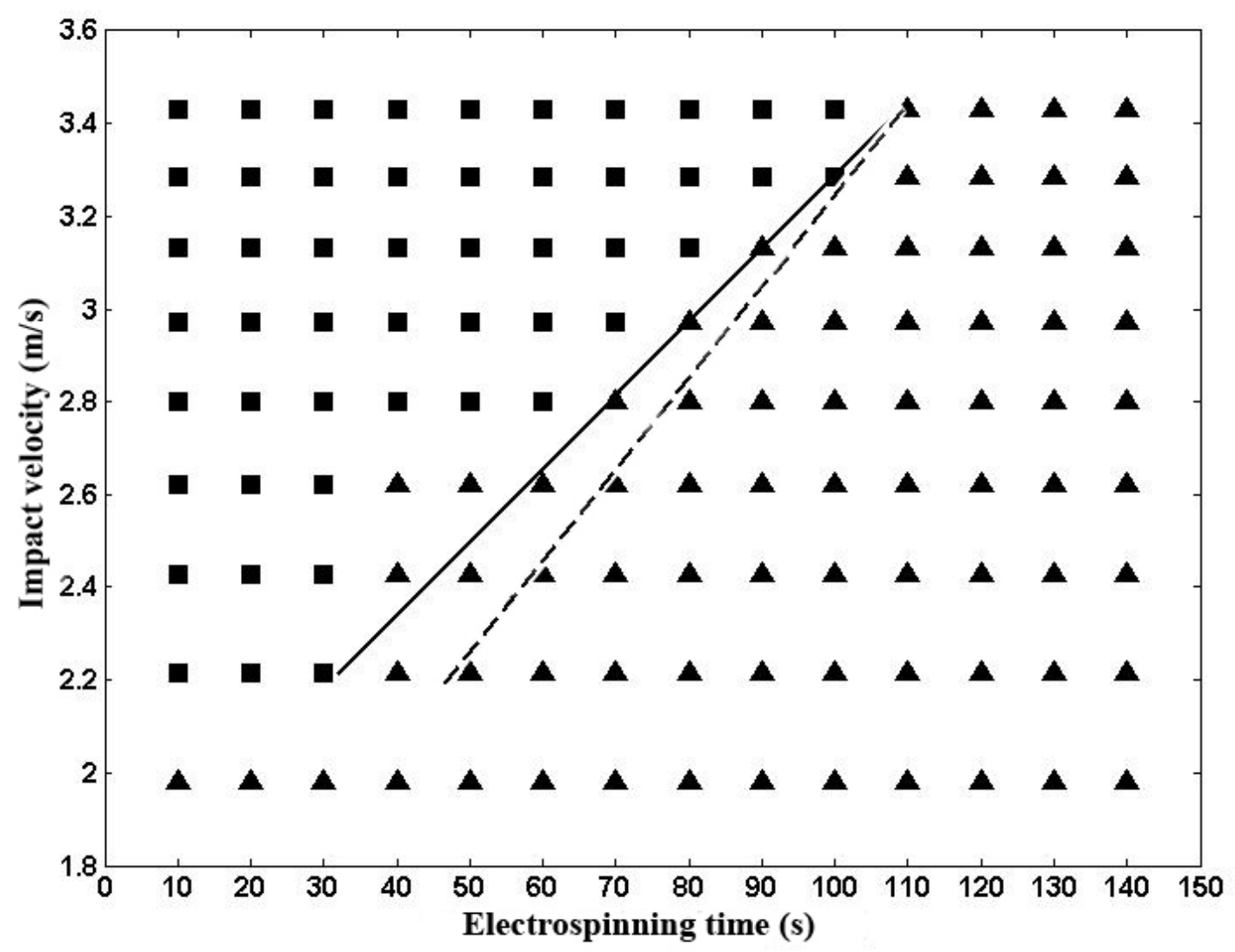

Fig. 18 Penetration chart for PCL and PAN nanofiber mats on bare Nylon grids. The solid line corresponds to PCL and the dashed line to PAN.

\subsection{Water Drop Iimpact onto Electrospun Teflon Nanofiber Mats Supported on Bare}

\section{Nylon grids}

Static contact angle of water drops on cast Teflon was measured as $115-120^{\circ}$ (Fig. S10a in ESI), whereas the static contact angle of water drops on the electrospun Teflon membrane on Nylon grid was in the range $140-150^{\circ}$ (Fig. S10b in ESI). Figure 19 shows the SEM micrograph of the electrospun $5 \mathrm{wt} \%$ Teflon AF 1600 nanofibers collected on a SEM stub. The fiber crosssectional diameter ranges from $400 \mathrm{~nm}$ to $1 \mu \mathrm{m}$. It can also be seen from the SEM images in Figs. $19 \mathrm{a} \& \mathrm{~b}$ that at some places the fibers flattened and ribbon-like structures appeared. The 
flattened structures could probably be merged nanofiber bundles which resulted from fibers landing at the counter-electrode while still wet due to an incomplete solvent evaporation. SEM images of Teflon nanofibers collected on a Nylon grid are shown in Fig. 19a. It can be seen that the pores in the grid were not entirely blocked by the nanofibers but rather diminished to the level of 3-6 $\mu \mathrm{m}$ when a 5-8 $\mu \mathrm{m}$ thick mat was electrospun. The mat is superhydrophobic as shown in Fig. S10 in ESI. Superhydrophobicity of Teflon nanofiber mats is also illustrated in Fig. 20a where water jet impacts obliquely at a relatively low velocity of 1-2 $\mathrm{m} / \mathrm{s}$ at the mat (cf. movie S1 in the Supporting Information). It is seen that the jet bounced back from the mat. Figure 20b shows blowing off of drops from the mat surface by low speed air blowing. 

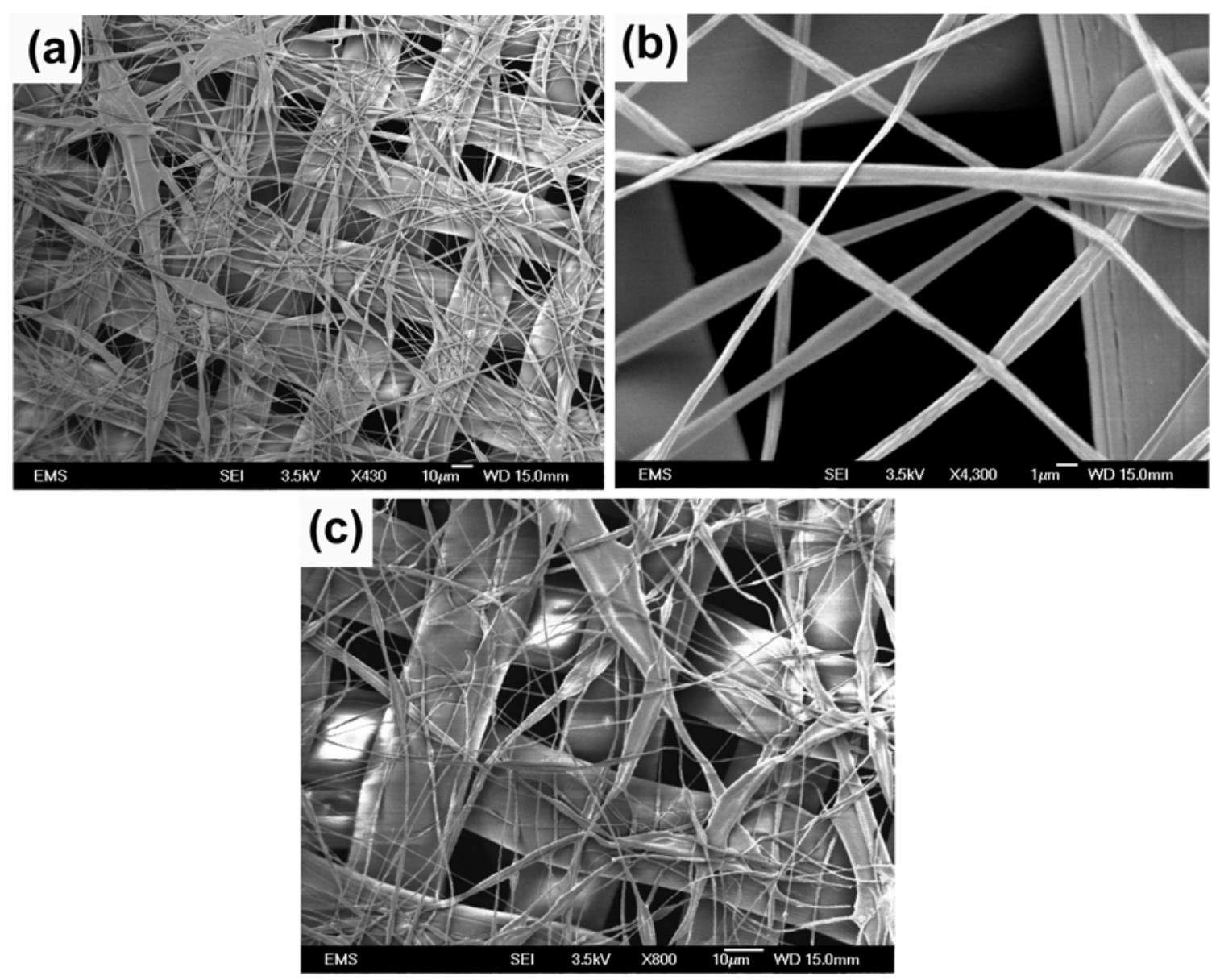

Fig. 19 SEM images of electrospun Teflon nanofiber mat collected on Nylon grid. The pore size of the Nylon grid is $20 \mu \mathrm{m}$ and the collected nanofibers effectively reduce the pore size of the substrate to 3-6 $\mu \mathrm{m}$. The thickness of the nanofiber mat is of the order of 5-8 $\mu \mathrm{m}$. (a) The overall view. (b) Teflon fibers over a pore of the Nylon grid. SEM images of electrospun Teflon nanofiber mat before (a) and after (c) drop impact at the impact location. The comparison of panels (a) and (c) does not show any visible damage to the mat caused by drop impact. 

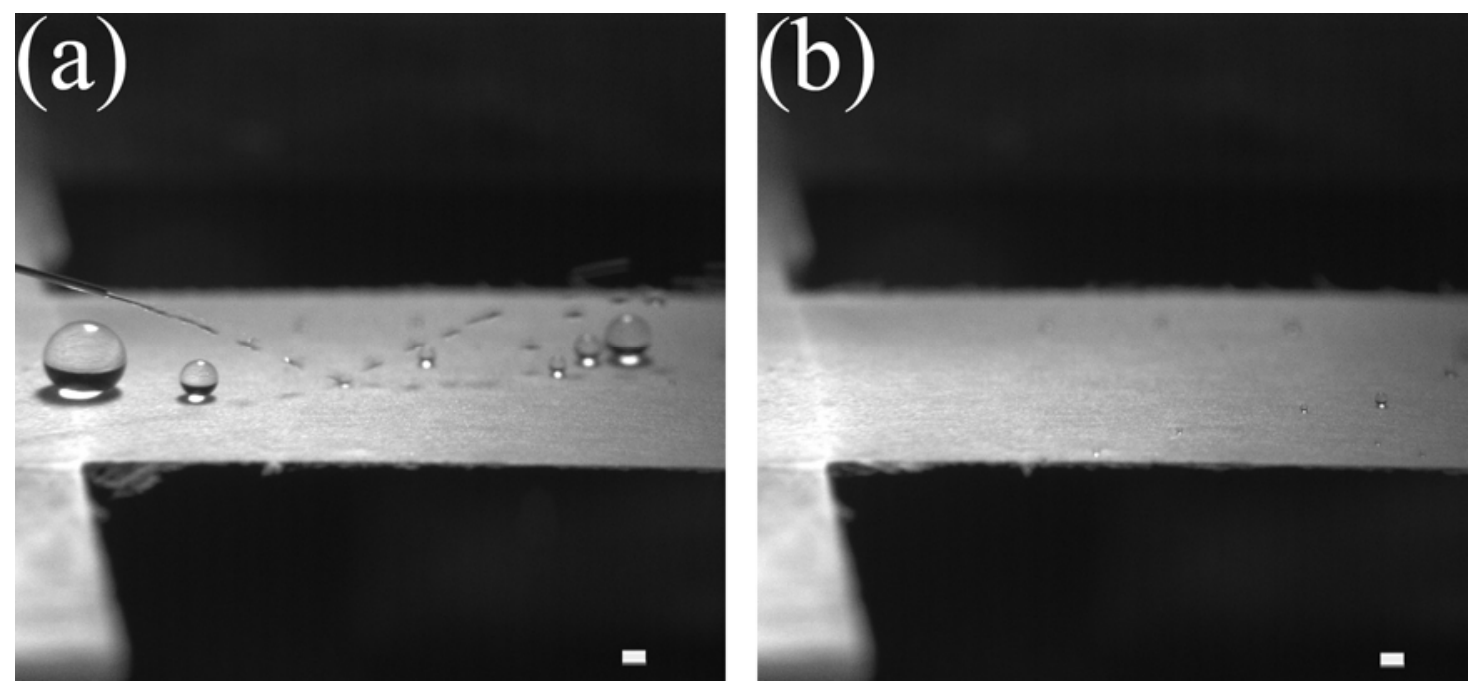

Fig. 20 Two frames from the movie (see in full in ESM) demonstrating superhydrophobicity of the Teflon nanofiber mat. A water jet issued from an inclined syringe manually (not using the setup of Fig. 1) impacts onto the Teflon mat with a velocity of 1-2 m/s. (a) Water jet is repelled from the Teflon nanofiber mat on a Nylon grid. (b) Drops are blown off from the Teflon nanofiber mat. Scale bars, $1 \mathrm{~mm}$.

Significant water repellency of Teflon nanofiber mats visible in Fig. 20 does not necessarily mean that such mats are impenetrable to water under dynamic conditions of drop impact. On the contrary, the mechanism of the accumulation of the kinetic energy of drop impact $^{15-17}$ should inevitably result in water penetration if the impact velocity is sufficiently high. In the following experiments, water drops were impacted onto Teflon nanofiber mats of thickness in the range of 5-7 $\mu \mathrm{m}$ deposited onto bare Nylon grids. Drops had the impact velocity of $2.82 \mathrm{~m} / \mathrm{s}$ and water penetration through the mat and grid was observed. Figure 21 shows the images of water drop impact onto Teflon mats at the impact velocity $\mathrm{V}=3.46 \mathrm{~m} / \mathrm{s}$. It is seen that the water drop partially penetrated through the Teflon nanofiber mat. After the impact the penetrated portion of water drop might retract back to the surface of the supporting Nylon grid or 
break off as a jet or individual secondary droplets (as in Fig. 21). The penetration patterns depended on the impact velocity and thickness of the nanofiber mat. After the impact, the portion of the water drop remaining on the nanofiber mat surface retracts and completely rebounds from the surface. The inspection of the nanofiber mat after drop penetration showed that no damage was caused to the nanofibers and that the porous structure after penetration resembles the one before the penetration which is evident from Figs. 19a\&c. The portion of the nanofiber mat shown in Figs. 19a\&c corresponds to the impact location. It only covers an area of $0.2 \mathrm{~mm} \times 0.2$ $\mathrm{mm}$. Some fibers are seen slightly re-oriented either by drop impact or water drying. However, it can be seen that no significant damage (big holes) was observed.

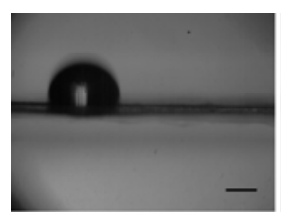

$\mathrm{t}=0 \mathrm{~ms}$

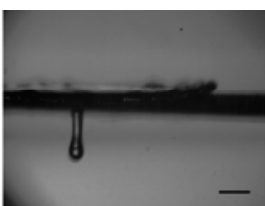

$\mathrm{t}=2 \mathrm{~ms}$

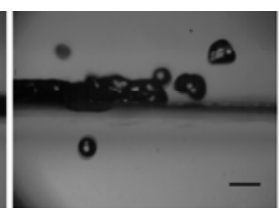

$\mathrm{t}=6 \mathrm{~ms}$

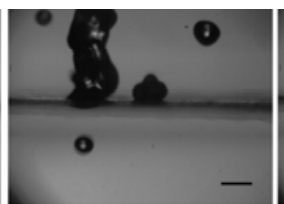

$\mathrm{t}=10 \mathrm{~ms}$

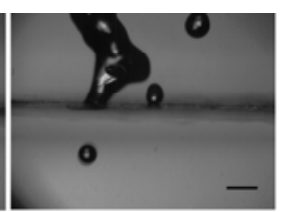

$\mathrm{t}=14 \mathrm{~ms}$

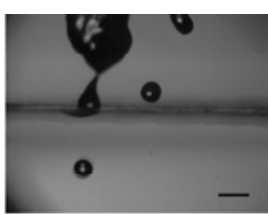

$\mathrm{t}=18 \mathrm{~ms}$

Fig. 21 Water drop impact onto electrospun Teflon nanofiber mat on Nylon grid. The impact velocity $\mathrm{V}=3.46 \mathrm{~m} / \mathrm{s}$. Scale bars, $1 \mathrm{~mm}$.

\section{Viscous Dissipation Inside the Pores and the Critical Thickness of}

\section{Nanofiber Mats}

In Refs. 15 and 17 it was shown that liquid penetration into pores of size $\delta$ after drop impact of size $\mathrm{D}$ at velocity $\mathrm{V}$ proceeds with the initial velocity $\mathrm{U}$, where

$$
\mathrm{U} \approx \mathrm{V} \frac{\mathrm{D}}{\delta}
$$


which is much higher than $\mathrm{V}$ in the cases where $\mathrm{D} / \delta>>1$. In particular, in the present case $\mathrm{D} \approx 0.1 \mathrm{~cm}$, whereas $\delta \approx 10^{-3} \mathrm{~cm}$ for the grids used, and $\delta \approx 10^{-4} \mathrm{~cm}$ for the nanofiber mats on them. Given $V \approx 1 \mathrm{~m} / \mathrm{s}$, the accumulation of the kinetic energy due to drop impact in flow into the pores ${ }^{15,17}$ can result in the initial penetration velocities of the order of $U \approx 100 \mathrm{~m} / \mathrm{s}$. This analysis can be extended, in principle, to the case when the drop penetrates into several pores simultaneously, which will diminish the value of $U$.

The entire kinetic energy brought by the penetrating water drop into the pores will be rapidly dissipated by viscous friction at the pore walls. As a result, a critical mat thickness should exist for any given pore size, which corresponds to the total dissipation of the initial kinetic energy. The following estimate demonstrates that. The kinetic energy $E_{k}$ brought by a water drop penetrating into the pores can be evaluated as

$$
\mathrm{E}_{\mathrm{k}} \approx \rho \mathrm{U}^{2} \mathrm{D}^{3} \approx \rho\left(\mathrm{V} \frac{\mathrm{D}}{\delta}\right)^{2} \mathrm{D}^{3}
$$

In the dynamic penetration the surface tension effects are negligible, and the only resistance to flow in the pores arises from viscous friction at the pore walls. The viscous shear stress $\sigma$ is estimated as

$$
\sigma \approx \mu \frac{\mathrm{U}}{\delta} \approx \frac{\mu}{\delta}\left(\mathrm{V} \frac{\mathrm{D}}{\delta}\right)
$$

The length of a tortuous pore is assumed to be of the order of the size of an impacting drop D. Then, the pore surface area is of the order of $\delta \mathrm{D}$, and the viscous friction force acting on liquid in a single pore is estimated as $\sigma \delta \mathrm{D}$. On the other hand, the number of pores through which liquid is penetrating is of the order of $(D / \delta)^{3}$, which makes the total viscous force of the order of $\sigma \delta \mathrm{D}(\mathrm{D} / \delta)^{3}$. The estimate of the number of pores takes into consideration the through pores and the pores leading sideways. Correspondingly, the work done by viscous forces while 
liquid has penetrated a mat of the thickness $h$ is of the order of $\sigma \delta \mathrm{D}(\mathrm{D} / \delta)^{3} \mathrm{~h}$, which represents itself the total viscous dissipation $\mathrm{E}_{\mathrm{d}}$. Using Eq. (3), we find that

$$
\mathrm{E}_{\mathrm{d}} \approx \frac{\mu}{\delta}\left(\mathrm{V} \frac{\mathrm{D}}{\delta}\right) \delta \mathrm{D}\left(\frac{\mathrm{D}}{\delta}\right)^{3} \mathrm{~h}
$$

In the mat of the critical thickness, the entire kinetic energy brought by a drop is fully dissipated by viscous forces, i.e. $\mathrm{E}_{\mathrm{k}} \approx \mathrm{E}_{\mathrm{d}}$. As a result, Eqs. (2) and (4) yield the critical mat thickness of the order of

$$
\mathrm{h}=\frac{\rho \mathrm{V} \delta^{2}}{\mu}
$$

It is instructive to see that the critical mat thickness does not depend on the impacting drop size. Taking for the estimates the pores of the order of $\delta \approx 10^{-3} \mathrm{~cm}$ and the impact velocity of the order of $\mathrm{V} \approx 1 \mathrm{~m} / \mathrm{s}$, we obtain from Eq. (5) for water the critical mat thickness $\mathrm{h} \approx 100 \mu \mathrm{m}$. According to Fig. S6 in ESI, all PAN nanofiber mats which were fully penetrated by water had thicknesses of the order of $10 \mu \mathrm{m}$, since they were deposited for less than $70 \mathrm{~s}$. This experimental result is within the range of the theoretical estimate. It is emphasized that the theoretical analysis of this section, and in particular, its result, Eq. (5), is novel, as to our knowledge.

\section{Conclusion}

Drop impacts of a single liquid drop in a range of the impact velocities from $1 \mathrm{~m} / \mathrm{s}$ to 3.46 $\mathrm{m} / \mathrm{s}$ were studied experimentally. The tests employed impacts onto bare Nylon grids (partially wettable), Teflon-coated Nylon grids, and Nylon grids covered with electrospun Polyacrylonitrile (PAN), Nylon 6/6, Polycaprolactone (PCL) and Teflon nanofiber mats, which covers a wide wettability range (from partially wettable to superhydrophobic). It was found experimentally that there exists a relatively low threshold velocity at which water drops fully 
penetrate (i.e. some water is disconnected from the rear side) through any of these micro-porous and nano-textured membranes irrespective of their wettability. It shows that after the threshold velocity has been surpassed, the static wettability plays only a secondary role in water penetration, which is mainly a dynamic process. In particular, it was shown that in the case of bare Nylon grids, water penetration happens at the impact velocities above the threshold value of $2.23 \mathrm{~m} / \mathrm{s}$. In the case of bare Teflon-coated Nylon grids there is water penetration at the impact velocities above the threshold value of $2.64 \mathrm{~m} / \mathrm{s}$. The other liquids studied (Fluorinert fluid FC 7500 and hexane) penetrated through the grids much easier than water, which possesses a higher surface tension and kinematic viscosity.

It was also shown that the threshold impact velocity for water penetration exists for the impacts onto electrospun nanofiber mats of PAN, Nylon 6/6, PCL and Teflon, which practically encompass the entire wettability range. This shows that water penetration (the dynamic wettability) always sets in above a relatively low threshold impact velocity, and an ultimate water-repellent fibrous medium is hardly possible. The less wettable the membrane is, the higher is the threshold velocity, however, it still stays below $3.5 \mathrm{~m} / \mathrm{s}$. An especially non-trivial result is that superhydrophobicity of the porous nano-textured Teflon skeleton with the interconnected pores is incapable to prevent water penetration due to drop impact, even at relatively low impact velocities close to $\mathrm{V}=3.46 \mathrm{~m} / \mathrm{s}$. It is also emphasized that electrospun nano-textured Teflon membranes, which represent themselves a relatively new nano-textured, superhydrophobic materials obtained two years ago, which possess very low hydraulic permeability, are shown to be incapable of fully repelling water under the dynamic conditions corresponding to drop impact.

A theoretical estimate is developed to evaluate the critical thickness of the nanofiber mat capable to fully dissipate the kinetic energy of penetrating liquid. The critical thickness is close 
to $100 \mu \mathrm{m}$. It was found from the experiments that the data are within the range of the theoretical estimate.

\section{Acknowledgment}

The current work is supported by the Nonwovens Cooperative Research Center (NCRC).

\section{References}

1. A. L. Yarin, G. G. Chase, W. Liu, S. V. Doiphode and D. H. Reneker, AIChE J., 2006, 52, $217-227$

2. D. F. Sherony, R. C. Kintner and D. T. Wasan, Surface Colloid Sci., 1978, 10, 99-161. 3. J. Pich, Aerosol Science, 1966, 223-285.

4. C. Tien, Granular Filtration of Aerosols and Hydrosols, Butterworths: Boston, 1989.

5. R. C. Brown, Air Filtration: An Integrated Approach to the Theory and Application of Fibrous Filters; Pergamon Press: Oxford,

6. S. S. Sareen, P. M. Rose, R. C. Gudesen, and R. C. Kintner, AIChE J., 1966, 12, 1045-1050.

7. L. A. Spielman and S. L. Goren, Ind. Eng. Chem. Fundam., 1972, 11, 66-72.

8. J. F. Bitten, J. Colloid Interface Sci., 1970, 33, 265-271.

9. J. I. Rosenfeld and D. T. Wasan, Can. J. Chem. Eng., 1974, 52, 3-10.

10. A. Marmur, The equilibrium contact angle. The Springer Handbook of Experimental Fluid Mechanics; (eds. Tropea, C.; Yarin, A.L.; Foss, J. ) Springer: Berlin 2007; Section 3.3.1, 106.

11. L. Jiang, Y. Zhao and J. Zhai, Angew. Chem.-Int. Ed., 2004, 43, 4338-4341. 
12. L. Gao and T. J. McCarthy, Langmuir, 2009, 25, 14105-14115.

13. D. H. Reneker, A. L. Yarin, E. Zussman and H. Xu, Adv. Appl. Mech., 2007, 41, 43-195.

14. R. Srikar, T. Gambaryan-Roisman, C. Steffes, P. Stephan, C. Tropea and A. L. Yarin, Int. J. Heat and Mass Transf., 2009, 52, 5814-5826.

15. A. Lembach, H. B. Tan, I. V. Roisman, T. Gambaryan-Roisman, Y. Zhang, C. Tropea and A. L. Yarin, Langmuir, 2010, 26, 9516-9523.

16. S. Sinha Ray, Y. Zhang and A. L. Yarin, Langmuir, 2011, 27, 215-226.

17. C. M. Weickgenannt, Y. Zhang, A. N. Lembach, I. V. Roisman, T. Gambaryan-Roisman, A. L. Yarin and C. Tropea, Phys. Rev. E, 2011, 83, 036305.

18. C.M. Weickgenannt, Y. Zhang, S. Sinha-Ray, I.V. Roisman, T. Gambaryan- Roisman, C. Tropea and A.L. Yarin, Phys. Rev. E, 2011, 84, 036310.

19. A. L. Yarin, Annu. Rev. Fluid Mech., 2006, 38, 159-192.

20. S. T. Thoroddsen, T. G. Etoh and K. Takehara, Annu. Rev. Fluid Mech., 2008, 40, 257-285.

21. W. M. Liu and Z. G. Guo, Appl. Phys. Lett., 2007, 90, 22311.

22. P. Tsai, S. Pacheco, C. Pirat, L. Lefferts and D. Lohse, Langmuir 2009, 25, 12293-12298.

23. D. Han and A. J. Steckl, Langmuir, 2009, 25, 9454-9462.

24. P. Tsai, R. C. A. van der Veen, M. van de Raa and D. Lohse, Langmuir 2010, 26, 1609016095.

25. T. P. N. Nguyen, P. Brunet, Y. Coffinier, R. Boukherroub, Langmuir 2010, 26, 18369-18373.

26. J. B. Lee, S. H. Lee, Langmuir, 2011, 27, 6565-6573.

27. R. Tadmor, Soft Matter, 2011, 7, 1577-1580.

28. R. Tadmor, P. Bahadur, A. Leh, H.E. N'guessan, R. Jaini and L. Dang, Phys. Rev. Lett., 2009, 103, 266101. 
29. T. Kim, K.Y. Suh, Soft Matter, 2009, 5, 4131-4135.

30. M.K. Kwak, H.-E. Jeong, T. Kim, H. Yoon and K.Y. Suh, Soft Matter, 2010, 6, 1849-1857.

31. R. Scheffler, N. S. Bell and W. Sigmund, J. Mater. Res., 2010, 25, 1595-1600.

32. Product information: DuPont Teflon AF Amorphous Fluoropolymers (http://www2.dupont.com/Teflon_Industrial/en_US/assets/downloads/h44587.pdf).

33. Electronic Markets Materials Division 3M Center, St. Paul, MN (www.3M.com/novec).

34. R. Bhardwaj, J. P. Longtin and D. Attinger, Int. J. Heat and Mass Transf., 2007, 50, 29122923. 